\title{
8 Simulations of voivodeship and oblast development trajectories. An analysis based on the gravity growth model
}

\author{
Svitlana Chugaievska, Katarzyna Filipowicz, \\ Tomasz Tokarski and Rafat Wista
}

\subsection{Introduction}

This analysis of the most important determinants of the spatial diversity of labor productivity in Poland and Ukraine was carried out on the basis of the gravitational model of economic growth proposed in the work by Mroczek et al. 2014 (cf. also Filipowicz 2019) and is a compilation of the gravitational trade models of Linnemann 1963, Poyhonen 1963 and Pulliainen 1963 with the neoclassical model of economic growth of Solow 1956.

The model under consideration is assumed to be, amongst others, an assumption that labor productivity depends both on the capital-labor ratio (as is the case in the neoclassical Solow growth model) and on the gravity effects affecting a given region. These (as in Newton's law of universal gravitation) are directly proportional to the economic potential of a given region (voivodeships or oblasts) and the economic potential of other regions, and is inversely proportional to the square of the geometric mean [geomean] of the distance between the capital of a given region and the capitals of other regions.

The gravitational growth model was used, inter alias, for analyzing the spatial diversity of the economic development of Polish voivodeships (Mroczek et al. 2014; Filipowicz 2019), Ukrainian oblasts (Chugaievska et al. 2017), the Balkan countries (Mroczek et al. 2015) and the EU countries (Wisła et al. 2018).

\subsection{Gravitational growth model}

In the gravitational model of economic growth, the following submissions are made regarding the long-term functioning of the economy (after Mroczek et al. 2014, see also Filipowicz 2019):

1 Labor productivity function (resulting from the Cobb-Douglas production function) is given by the formula: ${ }^{1}$

$$
\forall i \quad y_{i}(t)=a\left(g_{i}(t)\right)^{\beta}\left(k_{i}(t)\right)^{\alpha},
$$


where $y_{i}(t)$ means labor productivity in the region $i$ (i.e., in the Polish voivodeship or Ukrainian oblast) at the moment $t, a>0$ is a certain constant that has no direct economic interpretation, $g_{i}(t)$ are aggregate gravity effects, $k_{i}(t)$ is capital-labor ratio, and $\alpha \in(0,1)$ and $\beta \in(0,1)$ are elasticities of labor productivity in relation to capital-labor ratio and total gravitational effects. We also assume that $\beta<\frac{1-\alpha}{2}$, which means that the nontrivial steady state point of the system of differential equations (8.6) is (by the Grobman-Hartman theorem) asymptotically stable.

2 Total aggregate gravity effects affecting the region $i$ are the geometric mean of individual gravity effects connecting this region with the other regions, therefore:

$$
\forall i \quad g_{i}(t)=\sqrt[N-1-1]{\prod_{j \neq 1} g_{i j}(t)},
$$

where $g_{i j}(t)$ means individual gravity effects connecting the region $i$ with the region $j$.

3 The individual gravitational effects connecting the region $i$ with the region $j$ are directly proportional to the ratio of the economic potential of these regions (measured by their capital-labor ratio) and inversely proportional to the square of the distance between them (and exactly between their capitals). It follows that individual gravitational effects can be written as follows:

$\forall i, \quad j \wedge i \neq j \quad g_{i j}(t)=\frac{k_{i}(t) k_{j}(t)}{d_{i j}^{2}}$,

where $d_{i j}$ is the distance between the capital of the region $i$ and region $j$ (this distance was calculated from the Pythagorean theorem in a straight line connecting the capitals of voivodeships or oblasts).

4 The increase in capital-labor ratio $k_{i}$ is described by the Solow equation:

$\forall i \quad k_{i}(t)=s_{i} y_{i}(t)-\mu_{i} k_{i}(t)$

Where $s_{i} \in(0,1)$ is the investment rate in the region $i$, and $\mu_{i}>0$ is the decrease rate of the capital-labor ratio (which is the sum of the depreciation rate of capital and the growth rate of employment).

From Eqs. (8.1) to (8.3) we obtain the function of labor productivity:

$$
\forall i \quad y_{i}(t)=a \frac{\left(k_{i}(t)\right)^{\alpha+\beta} \prod_{j \neq 1}\left(k_{j}(t)\right)^{\beta /(N-1)}}{\bar{d}_{i}^{2 \beta}},
$$

where $\bar{d}_{i}$ is the geometric mean distance from the capital of the region $i$ and from the capitals of the other regions. By inserting Eq. (8.5) into the 
equations for the increase of capital-labor ratio (8.4), we arrive at the following system of differential equations:

$$
\forall i \quad k_{i}(t)=s_{i} a \frac{\left(k_{i}(t)\right)^{\alpha+\beta} \prod_{j \neq 1}\left(k_{j}(t)\right)^{\beta /(N-1)}}{\bar{d}_{i}^{2 \beta}}-\mu_{i} k_{i}(t) .
$$

The system of differential equations (8.6) has two steady state points: trivial at the beginning of the $\mathrm{N}$-dimensional coordinate system and non-trivial in which dependencies are met (after Mroczek et al. 2014).

$$
\forall i \quad \ln k_{i}^{*}=\frac{\frac{\beta}{(N-1)(1-\alpha-2 \beta)} \sum_{j} \ln \frac{a s_{j}}{\mu_{j} \bar{d}_{j}^{2 \beta}}+\ln \frac{a s_{i}}{\mu_{i} \bar{d}_{i}^{2 \beta}}}{1-\alpha-\frac{N-2}{N-1} \beta} .
$$

As already mentioned, using the Grobman-Hartman theorem (Grobman 1999: 219-221) it can be shown that the non-trivial stationary point determined by Eq. (8.7) is characterized by an asymptotic stability (Mroczek et al. 2014). So, this point sets the long-run equilibrium of the gravitational model of economic growth.

The following conclusions can be drawn from Eq. (8.7). The level of capital-labor ratio in the i-region $k_{i}^{*}$ is higher when the investment rate in this region $s_{i}$ is higher, of the decrease rate of investment in other regions $s_{j}$ and the lower the capital decrease rate in $i$-the region $\mu_{i}$ and the decrease rate in other regions $\mu_{j}$. The size of the long-term capital-labor ratio in each region is also affected by its geographical location, which follows from the fact that the more centrally located region (i.e., the lower the average geometric distance $\bar{d}_{i}$ ), the higher is the long-term capital-labor ratio.

\subsection{The diversity of the capital-labor ratio, gravitational effects and investment rates}

Since the key variables in the gravitational model of economic growth are capital-labor ratio and gravitational effects, before simulating the trajectory of labor productivity in voivodeships and oblasts, a brief description of the spatial diversity of these macroeconomic variables in Poland and Ukraine seems appropriate. These analyses (due to the availability of relevant statistical data on the websites of the Polish and Ukrainian Statistical Offices) concern the years 2004-2015 (in the case of Poland) and 2004-2017 (in the case of Ukraine).

\subsubsection{Poland}

In the years 2004-2016 there were significant disproportions between voivodeships due to the level of capital-labor ratio. This variable (on average over the whole period of time studied) ranged from 129,800 PLN in the 


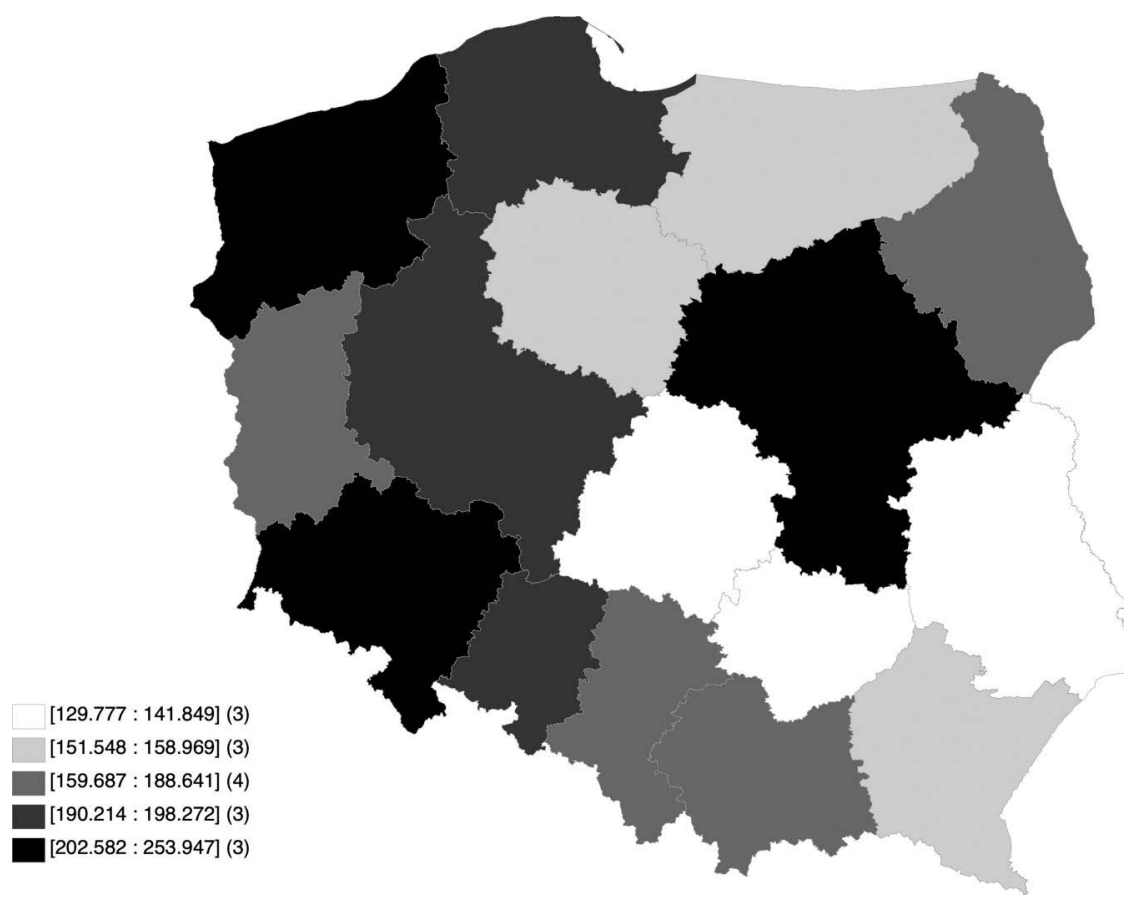

Map 8.1 Diversification of capital-labor ratio in voivodeships in 2004-2016 (thousand PLN, according to 2014 prices).

Source: Our own estimates based on: https://bdl.stat.gov.pl/BDL/start (access: 2019-12-30).

Lubelskie Voivodeship up to 253,900 PLN in the Mazowieckie Voivodeship. In addition to the capital of the Mazowieckie Voivodeship, the capitallabor ratio exceeded a level of 200,000 PLN in the Zachodniopomorskie (213,000 PLN) and Dolnośląskie (202,600 PLN) voivodeships. The following voivodeships all exceeded a level of 190,000 PLN, that is, the Opolskie (198,300 PLN), Pomorskie (190,400 PLN) and Wielkopolskie (190,200 PLN) voivodeships. The lowest levels of this variable, however, were in the Łódzkie (141,800 PLN) and Świętokrzyskie (133,900 PLN) voivodeships. The capital-labor ratio did not exceed a level of 160,000 PLN in the following voivodeships: Małopolskie (159,700 PLN), Warmińsko-Mazurskie (159,900 PLN), Kujawsko-Pomorskie (157,700 PLN) and Podkarpackie (151,500 PLN, see Map 8.1).

Hence, we may come to a more general conclusion that (except for the Łódzkie and Świętokrzyskie voivodeships) the voivodeships west of the Vistula (Wisła) river were characterized by a higher level of capital-labor ratio.

The spatial diversity of gravitational effects is the result of two factors. These factors are the economic potential of a given region (measured by its capital-labor ratio) and its geographic location. 


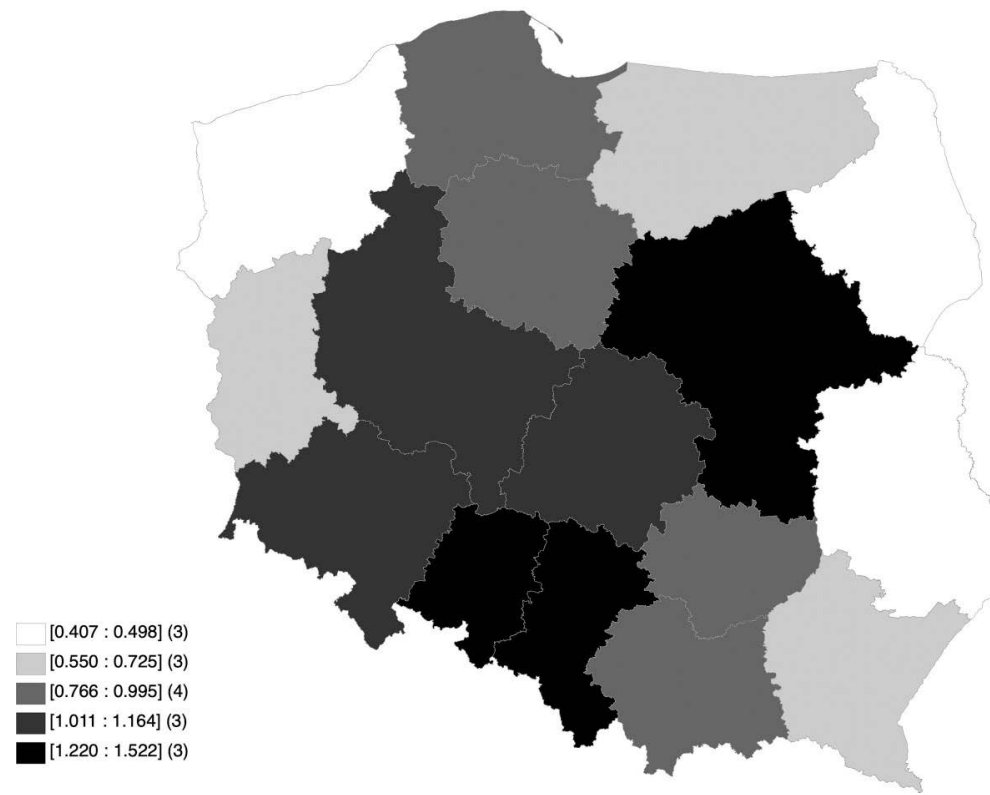

Map 8.2 Differentiation of gravitational effects in voivodeships in 2004-2016 (million $\mathrm{PLN}^{2} /$ mingeo $^{2}$ according to 2014 prices).

Source: Our own estimates based on: https://bdl.stat.gov.pl/BDL/start (access: 2019-12-30).

The highest levels of gravitational effects in Poland were found in the following voivodeships: ${ }^{2}$ Mazowieckie (1.522 million $\mathrm{PLN}^{2} / \mathrm{mingeo}^{2}$ ), Śląskie (1.243 million $\mathrm{PLN}^{2} / \mathrm{mingeo}^{2}$ ) and Opolskie (1.220 million $\mathrm{PLN}^{2} / \mathrm{mingeo}^{2}$ ). The high level of the feature in question was also characteristic of the Łódzkie (1.164 million $\mathrm{PLN}^{2} / \mathrm{mingeo}^{2}$ ), Dolnośląskie (1.075 million $\mathrm{PLN}^{2} / \mathrm{mingeo}^{2}$ ) and Wielkopolskie (1.011 million $\mathrm{PLN}^{2} /$ mingeo $^{2}$ ) voivodeships. Low and very low levels of gravitational effects were found in peripheral regions, both in the east and in the west of Poland. These were the following voivodeships: Warmińsko-Mazurskie ( 0.725 million $\mathrm{PLN}^{2} /$ mingeo $\left.^{2}\right)$, Podkarpackie $(0.573$ million $\mathrm{PLN}^{2} /$ mingeo $^{2}$ ), Lubuskie ( 0.550 million $\mathrm{PLN}^{2} / \mathrm{mingeo}^{2}$ ), Lubelskie $\left(0.498\right.$ million $\mathrm{PLN}^{2} /$ mingeo $\left.^{2}\right)$, Zachodniopomorskie $\left(0.424\right.$ million $\mathrm{PLN}^{2} /$ mingeo ${ }^{2}$ ) and Podlaskie (0.407 million $\mathrm{PLN}^{2} /$ mingeo $^{2}$, see Map 8.2).

In the following numerical simulations of labor productivity, in addition to internal gravitational effects, external gravitational effects were also included, connecting voivodeships with Poland's largest economic partner, that is, Germany. ${ }^{3}$ These effects are also included in the estimation of production function parameters and used to determine the development trajectories of voivodeships under various scenarios regarding the economic growth in Germany.

External gravitational effects indicate which voivodeships are potentially most affected by the German economy. By far the highest external 


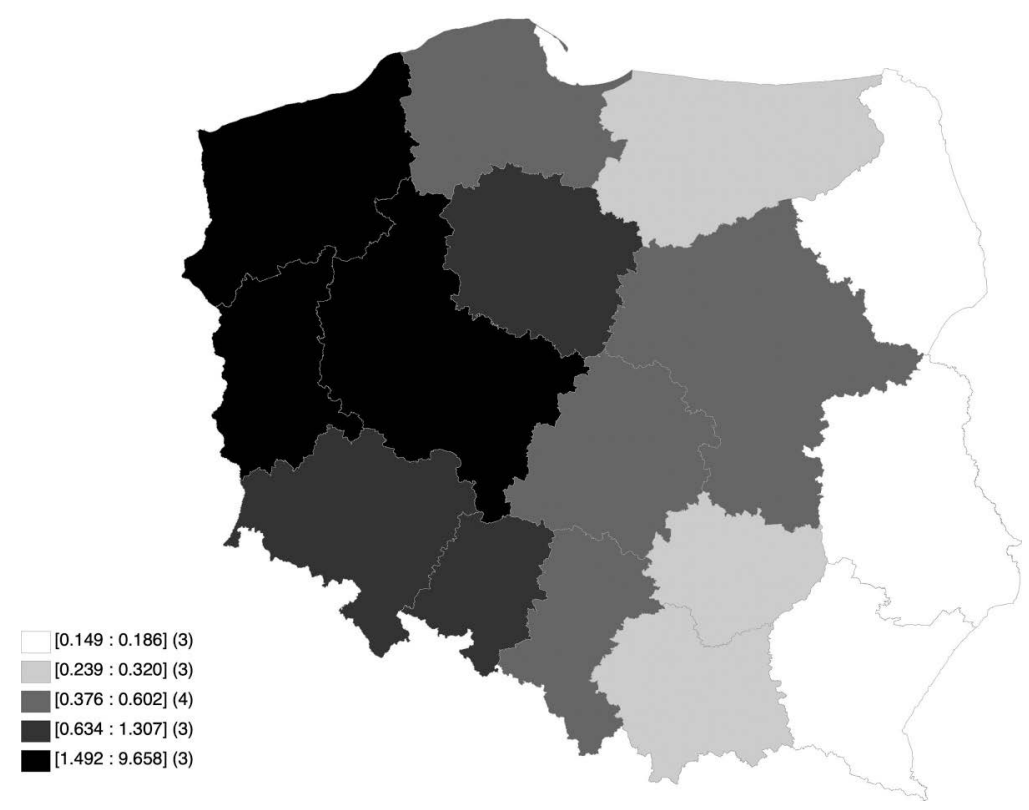

Map 8.3 External gravitational effects in voivodeships in 2004-2016 (million PLN ${ }^{2}$ / mingeo ${ }^{2}$ according to 2014 prices).

Source: Our own estimates based on: https://bdl.stat.gov.pl/BDL/start (access: 2019-12-30).

gravitational effects were characteristic of the border voivodeships in the west of Poland: the Zachodniopomorskie (9.658 million $\mathrm{PLN}^{2} / \mathrm{mingeo}^{2}$ ) and Lubuskie (4.435 million $\mathrm{PLN}^{2} /$ mingeo $^{2}$ ) voivodeships. The Wielkopolskie (1.492 million $\left.\mathrm{PLN}^{2} / \mathrm{mingeo}^{2}\right)$ and Dolnośląskie $\left(1.307\right.$ million $\mathrm{PLN}^{2} / \mathrm{min}-$ $\mathrm{geo}^{2}$ ) voivodeships also achieved a high level of this feature. Low external gravitational effects were observed in the following voivodeships: Małopolskie $\left(0.320\right.$ million $\mathrm{PLN}^{2} /$ mingeo $\left.^{2}\right)$, Warmińsko-Mazurskie $(0.302$ million $\left.\mathrm{PLN}^{2} / \mathrm{mingeo}^{2}\right)$ and Świętokrzyskie $\left(0.239\right.$ million $\left.\mathrm{PLN}^{2} / \mathrm{mingeo}^{2}\right)$. The weakest benefits from the impact of the German economy were recorded in the peripheral voivodeships in eastern Poland, that is, in the Podkarpackie $\left(0.186\right.$ million $\left.\mathrm{PLN}^{2} / \mathrm{mingeo}^{2}\right)$, Podlaskie $\left(0.166\right.$ million $\left.\mathrm{PLN}^{2} / \mathrm{mingeo}^{2}\right)$ and Lubelskie (0.149 million $\mathrm{PLN}^{2} /$ mingeo $^{2}$, see Map 8.3) voivodeships.

Because, according to Solow's Neoclassical Growth Model (1956) (but also in accordance with Mankiw et al. growth models (1992), and Nonneman's, Vanhoudt's (1996), or the gravitational model of economic growth used here), the investment rate is a key variable that determines the rate of capital accumulation and the rate of economic growth, one should also look at the spatial diversity of this variable in Polish voivodeships and Ukrainian oblasts.

In the years 2004-2015, the range between the highest and lowest investment rate (calculated as the share of investment in GDP) in voivodeships 


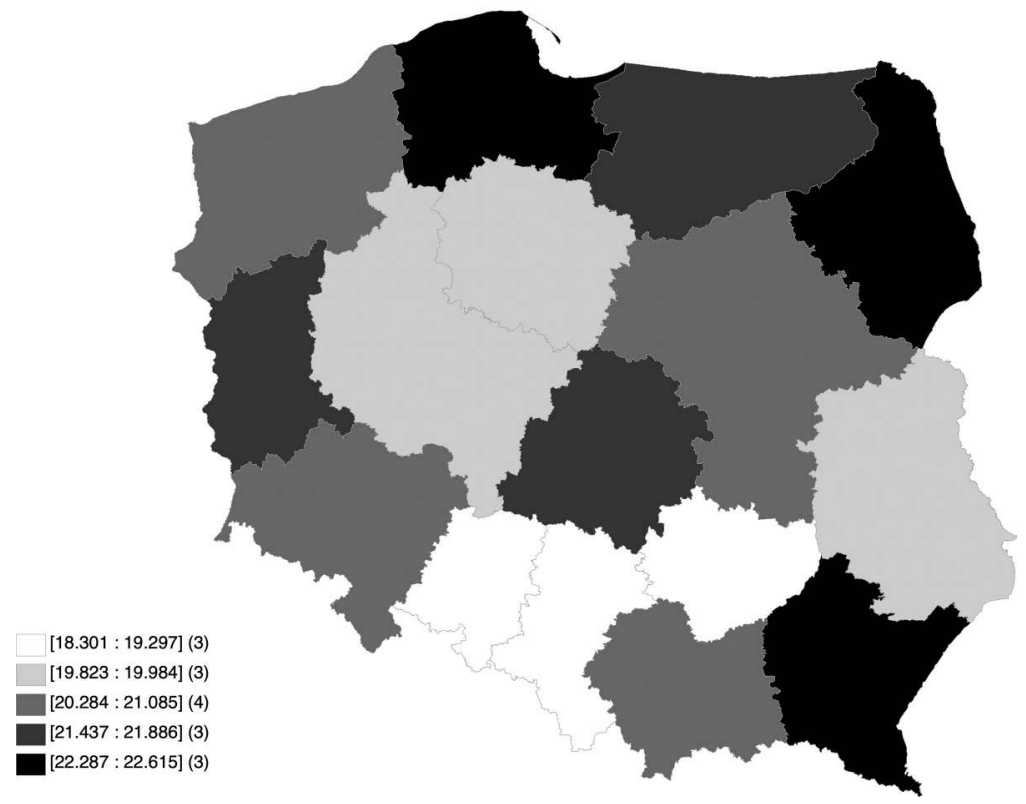

Map 8.4 Investment rates in voivodeships in 2004-2015 (\%).

Source: Our own estimates based on: https://bdl.stat.gov.pl/BDL/start (access: 2019-12-30).

was 4.3 percentage points, as these rates ranged from $18.3 \%$ (Śląskie Voivodeship) to $22.6 \%$ (Podlaskie Voivodeship). In as many as 11 voivodeships, investment rates exceeded $20 \%$. These were the following voivodeships: Podlaskie (22.6\%), Podkarpackie (22.4\%), Pomorskie (22.3\%), WarmińskoMazurskie (21.9\%), Lubuskie (21.6\%), Łódzkie (21.4\%), Zachodniopomorskie (21.1\%), Dolnośląskie (20.4\%), Małopolskie (20.3\%), Mazowieckie $(20.3 \%)$ and Kujawsko-Pomorskie (20.0\%). The lowest investment rate was recorded in the Śląskie Voivodeship (18.3\%, see Map 8.4).

\subsubsection{Ukraine}

Map 8.5 illustrates the spatial differentiation of capital-labor ratio in Ukraine. We can reach the following conclusions from this map: By far the highest level of capital-labor ratio was in the City of Kyiv (670,600 UAH). The group of oblasts with a high value of this feature also included the Kyiv Oblast (256,300 UAH) in northern Ukraine, and the Donetsk (243,500 UAH) in the east of Ukraine, and Dnipropetrovsk (227,100 UAH) and Poltava (191,000 UAH) oblasts in central Ukraine. A high (for Ukrainian conditions) value of this feature was recorded in the Zaporizhzhya (190,400 UAH), Luhansk (181,300 UAH) and Kharkiv (169,700 UAH) oblasts in 


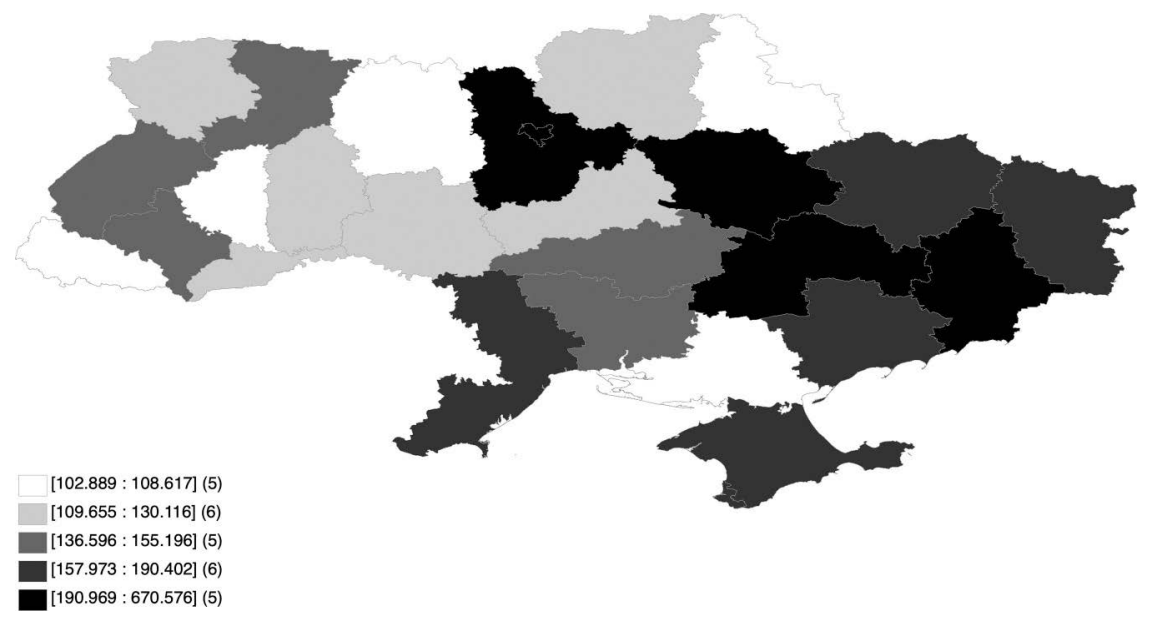

Map 8.5 Diversification of capital-labor ratio in oblasts in 2004-2017 (thousand UAH, according to 2016 prices).

In the case of the ARC and Sevastopol in 2004-2013.

Source: Our own estimates based on: http://www.ukrstat.gov.ua/ (access: 2019-12-30).

eastern Ukraine and the city of Sevastopol (184,300 UAH), Odesa Oblast $(179,900 \mathrm{UAH})$ and the Autonomous Republic of Crimea (169,700 UAH) in the south. Thus, all oblasts with the highest or high value of capital per employee were located in Left-bank Ukraine or on the Black Sea.

The group of oblasts with the lowest level of capital-labor ratio was composed of the following oblasts: Zakarpattia (102,900 UAH) and Ternopil $(104,100 \mathrm{UAH})$ in western Ukraine, Kherson (104,300 UAH) in the south and Zhytomyr (104,500 UAH) and Sumy (108, $600 \mathrm{UAH})$ in the north of Ukraine. A low level of capital-labor ratio also characterized the Vinnytsya $(109,700 \mathrm{UAH})$ and Cherkasy (117,300 UAH) oblasts in central Ukraine, the Volyn (117,300 UAH), Chernivtsi (121,500 UAH) and Khmelnytskiy (130,100 UAH) oblasts in the west of the country, and the Chernihiv (119,300 UAH) Oblast in the north of Ukraine. Thus, oblasts with a low or very low level of capital-labor ratio were located mainly on the Right-bank of Ukraine.

Map 8.6 illustrates the spatial differentiation of national gravitational effects in Ukraine. This map shows that the highest national gravitational effects were observed in the oblasts located in the Dnieper valley (Kyiv 1.628 million $\mathrm{UAH}^{2} /$ mingeo $^{2}$ and Kyiv Oblast ${ }^{4} 0.698$ million $\mathrm{UAH}^{2} / \mathrm{mingeo}^{2}$, Dnipropetrovsk 0.452 million $\mathrm{UAH}^{2} /$ minge $^{2}$, Poltava 0.388 million $\mathrm{UAH}^{2} /$ mingeo ${ }^{2}$ and Kirovohrad 0.380 million $\mathrm{UAH}^{2} / \mathrm{mingeo}^{2}$ ). This resulted both from their central geographical location and from the very high economic potential (in particular) of Kyiv and the Kyiv and Dnipropetrovsk oblasts (see also Chugaievska et al. 2017). 


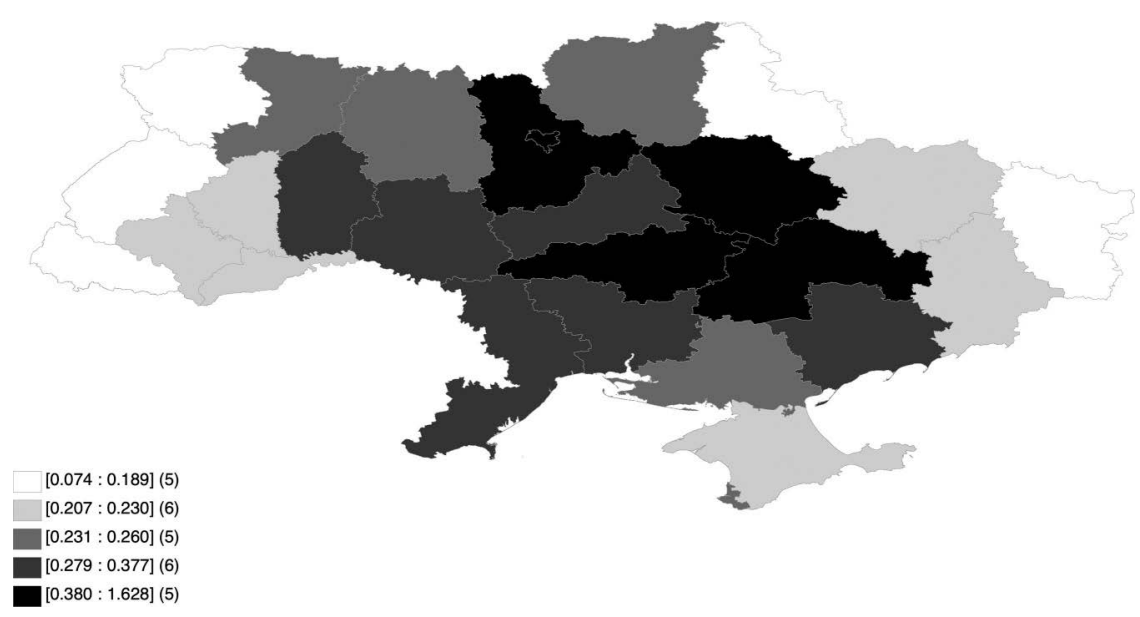

Map 8.6 Differentiation of national gravitational effects in the oblasts in 2004-2017 (million $\mathrm{UAH}^{2} / \mathrm{mingeo}^{2}$, according to 2016 prices).

In the case of the ARC and Sevastopol in 2004-2013.

Source: Our own estimates based on: http://www.ukrstat.gov.ua/ (access: 2019-12-30).

In contrast, the group of oblasts with the lowest national gravitational effects was composed of the following oblasts: Zakarpattia $\left(0.074\right.$ million $\mathrm{UAH}^{2} /$ minge $\left.{ }^{2}\right)$, Volyn $\left(0.188\right.$ million $\mathrm{UAH}^{2} /$ mingeo $\left.^{2}\right)$ and Lviv $\left(0.189\right.$ million $\mathrm{UAH}^{2} /$ minge $\left.{ }^{2}\right)$ in the west of Ukraine; Luhansk $\left(0.114\right.$ million $\left.\mathrm{UAH}^{2} / \mathrm{mingeo}^{2}\right)$ in the east; and Sumy $\left(0.173\right.$ million $\mathrm{UAH}^{2} /$ mingeo $\left.^{2}\right)$ in the north of the country.

When analyzing the impact of external gravitational effects on Ukrainian oblasts, two of Ukraine's most important economic partners, that is, Russia and Poland, were taken into account. ${ }^{5}$

The external gravitational effects flowing from Russia are illustrated in Map 8.7. The following conclusions can be drawn from this map: First of all, Kyiv had by far the highest level of these effects (1.437 million $\mathrm{UAH}^{2} /$ mingeo ${ }^{2}$ ). Second, a very high level of these effects was recorded in the Kharkiv $\left(0.781\right.$ million $\mathrm{UAH}^{2} /$ minge $\left.^{2}\right)$, Donetsk $\left(0.685\right.$ million $\mathrm{UAH}^{2} /$ minge $\left.{ }^{2}\right)$, Poltava $\left(0.661\right.$ million $\mathrm{UAH}^{2} /$ mingeo $\left.^{2}\right)$ and Dnipropetrovsk $(0.625$ million $\mathrm{UAH}^{2} /$ mingeo $^{2}$ ) oblasts, located in eastern and central Ukraine. Third, the lowest value of this feature was observed in the oblasts located in the west of Ukraine, in particular in the Zakarpattia $\left(0.059\right.$ million $\mathrm{UAH}^{2} /$ mingeo $\left.{ }^{2}\right)$, Ternopil ( 0.093 million $\mathrm{UAH}^{2} /$ mingeo $\left.^{2}\right)$, Chernivtsi $(0.104$ million $\mathrm{UAH}^{2} /$ mingeo $\left.^{2}\right)$, Ivano-Frankivsk $\left(0.105\right.$ million $\left.\mathrm{UAH}^{2} / \mathrm{mingeo}^{2}\right)$ and Volyn $\left(0.109\right.$ million $\left.\mathrm{UAH}^{2} / \mathrm{mingeo}^{2}\right)$ oblasts. Fourth, the external gravitational effects flowing from Russia had a much stronger impact on the Left-bank Ukraine and the Odesa and Mykolayiv coastal regions than on the rest of the country. This was due to historical (stronger economic links of the Leftbank of Ukraine with the rest of the Romanov Empire before World War I 


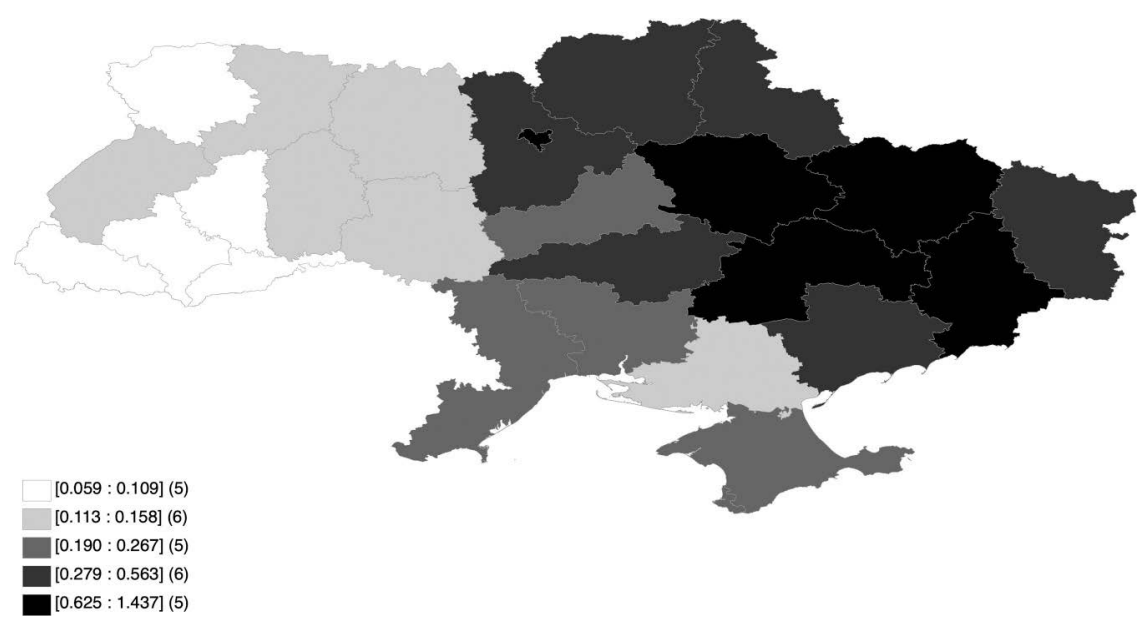

Map 8.7 External gravitational effects from Russia in oblasts in the years 20042017 (million $\mathrm{UAH}^{2} / \mathrm{mingeo}^{2}$, according to 2016 prices).

In the case of the ARC and Sevastopol in 2004-2013

Source: Our own estimates based on: http://www.ukrstat.gov.ua/ (access: 2019-12-30).

and with the other Soviet republics after the October Revolution in Russia), geographical (these oblasts are closer to Russia) and economic connections (they are usually characterized by a higher level of economic development than from the Right-bank of Ukraine).

Considering the external gravitational effects flowing from Poland (Map 8.8), the following conclusions can be drawn: These effects had the strongest impact on the Lviv (1.584 million $\mathrm{UAH}^{2} /$ mingeo $^{2}$ ), Zakarpattia $\left(1.073\right.$ million $\mathrm{UAH}^{2} /$ mingeo $\left.^{2}\right)$, Volyn $\left(0.884\right.$ million $\mathrm{UAH}^{2} /$ mingeo $\left.^{2}\right)$ and Ivano-Frankivsk $\left(0.866\right.$ million $\mathrm{UAH}^{2} /$ mingeo $\left.^{2}\right)$ oblasts in western Ukraine and on the City of Kyiv $\left(1,166\right.$ million $\mathrm{UAH}^{2} /$ mingeo $\left.^{2}\right)$. The impact of these effects on the Lviv, Volyn and Ivano-Frankivsk oblasts (but also on the Rivne 0.688 million $\mathrm{UAH}^{2} / \mathrm{mingeo}^{2}$ and Ternopil 0.574 million $\mathrm{UAH}^{2} /$ minge $^{2}$ ) resulted both from historical reasons (these regions belonged to Poland in the interwar period) and geographical causes (their close proximity to the Polish border). The substantial impact of gravitational effects in the Zakarpattia Oblast was due to a geographical factor (although it seems that this oblast, for historical reasons, is more strongly influenced by Hungary, Slovakia or Czechia than Poland), and in Kyiv due to its economic potential. The weakest external gravitational effects flowing from Poland affected the eastern oblasts of Luhansk $\left(0.086\right.$ million $\left.\mathrm{UAH}^{2} / \mathrm{mingeo}^{2}\right)$ and Kharkiv $\left(0.109\right.$ million $\mathrm{UAH}^{2} /$ mingeo $\left.^{2}\right)$ in the east of Ukraine, in the south the Kherson Oblast $\left(0.098\right.$ million $\left.\mathrm{UAH}^{2} / \mathrm{mingeo}^{2}\right)$ and the Autonomous Republic of Crimea 0.099 million $\mathrm{UAH}^{2} / \mathrm{mingeo}^{2}$ ) and the Sumy Oblast located in northern Ukraine $\left(0.087\right.$ million $\left.\mathrm{UAH}^{2} / \mathrm{mingeo}^{2}\right)$. Thus, 


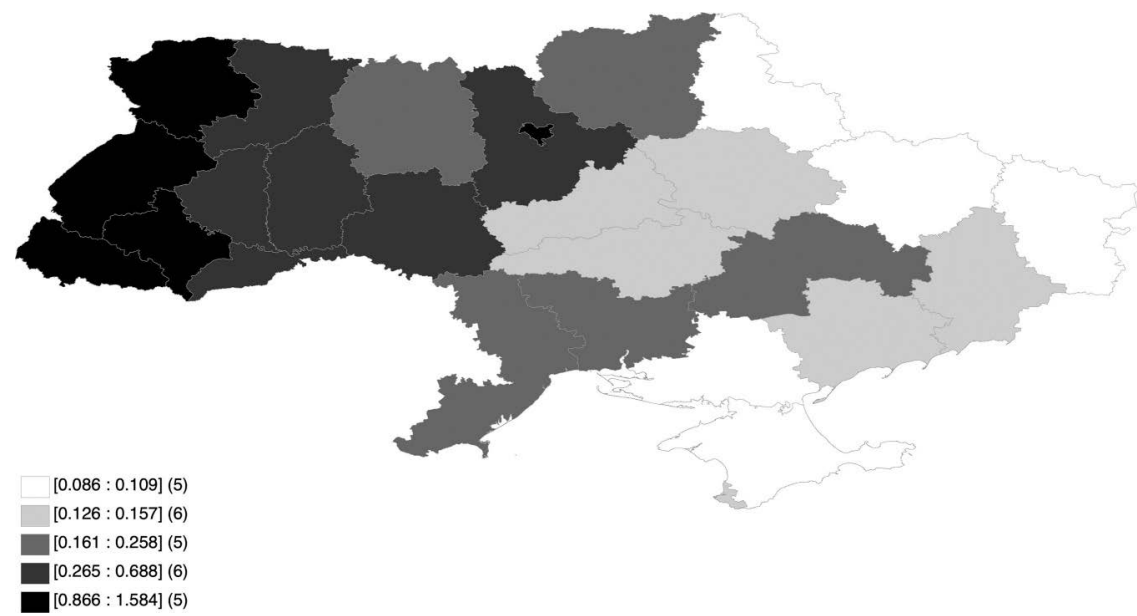

Map 8.8 External gravitational effects from Poland in oblasts in the years 20042017 (million $\mathrm{UAH}^{2} / \mathrm{mingeo}^{2}$, according to 2016 prices).

In the case of the ARC and Sevastopol in 2004-2013.

Source: Our own estimates based on: http://www.ukrstat.gov.ua/ (access: 2019-12-30).

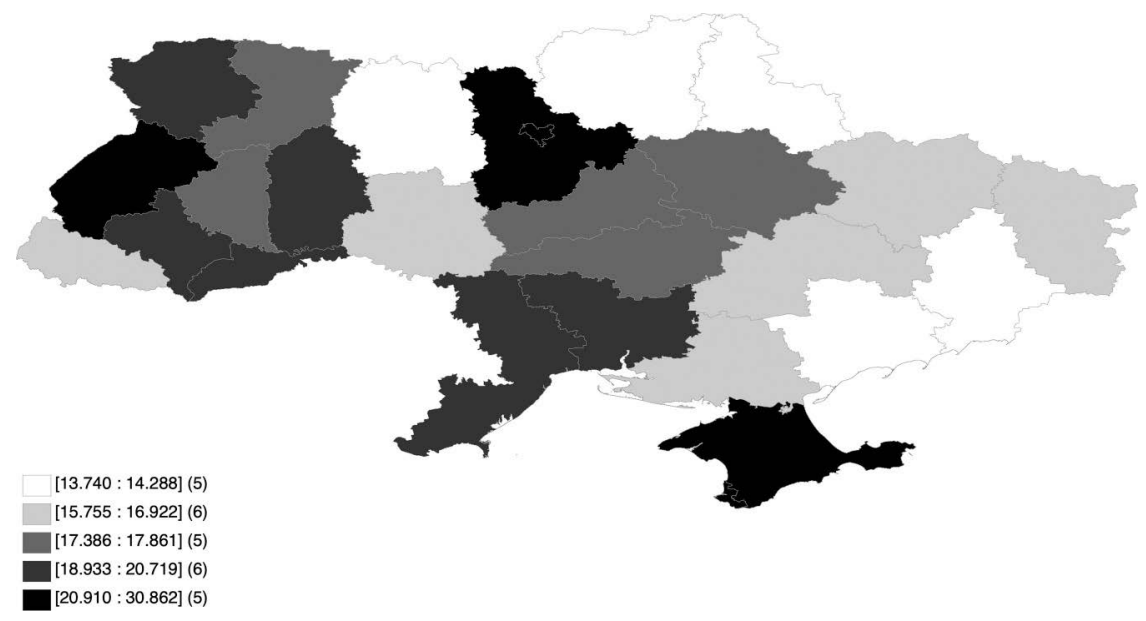

Map 8.9 The investment rates in Ukrainian oblasts in 2004-2017 (\%). In the case of the ARC and Sevastopol in 2004-2013.

Source: Our own estimates based on: http://www.ukrstat.gov.ua/ (access: 2019-12-30).

due to both geographical and historical factors, the external gravitational effects flowing from Poland had a significantly greater impact on western Ukraine than on other oblasts.

The average investment rates in the oblasts in 2004-2017 are illustrated on Map 8.9. This map shows that the Autonomous Republic of Crimea (30.9\%) and Sevastopol $(20.9 \%)$ had the highest level of this value in the south of 
Ukraine, while the Kyiv Oblast (30.5\%) and the City of Kyiv (23.8\%) had the highest value of this feature in northern, and the Lviv Oblast (21.3\%) in western Ukraine. The lowest shares of investment in GDP were recorded in the Sumy (13.7\%), Chernihiv (14.0\%) and Zhytomyr (14.2\%) oblasts in northern Ukraine as well as the Zaporizhzhya (14.2\%) and Donetsk (14.3\%) oblasts in the east of Ukraine.

\subsection{Calibration of model parameters}

The parameters of the gravitational model of economic growth were calibrated based on historical data for voivodeships from 2004 to 2015 or oblasts from 2004 to 2017. The labor productivity function includes both domestic gravitational effects and foreign gravitational effects related to the impact of the German or Russian or Polish economy. In the case of Poland, this function is described by the following equation:

$$
y_{i t}=a\left(k_{i t}\right)^{\alpha}\left(g_{i t}\right)^{\beta}\left(g_{i t}^{N}\right)^{\gamma}
$$

or after $\log$ in:

$$
\ln y_{i t}=\ln a+\alpha \ln k_{i t}+\beta \ln g_{i t}+\gamma \ln g_{i t}^{N},
$$

where: $a>0$ means total factor productivity, $k_{i t}$ is capital-labor ratio in the $i$-this region in year $t, g_{i t}$ is the total national gravitational effects in the $i$-this region in year $t,{ }_{i t}^{N}$ is the foreign gravitational effects from Germany in the $i$-this region in the year $t$. The parameters of this Eq. (8.8) were estimated by two methods - the ordinary least squares (OLS) method and the generalized method of moments (GMM). The results of the estimates are presented in Table 8.1.

Table 8.1 Estimates of the parameters of Eq. (8.1) for Poland

\begin{tabular}{lcc}
\hline Explanatory variables & OLS & $G M M$ \\
\hline $\ln a$ & $0.532^{* *}$ & $0.437^{*}$ \\
& $(2.325)^{* *}$ & $(1.759)^{* * *}$ \\
$\ln k_{i t}$ & $0.783^{* *}$ & $0.802^{* *}$ \\
& $(17.963)^{* *}$ & $(16.957)^{* *}$ \\
$\ln g_{i t}$ & $0.115^{* * *}$ & $0.113^{* * *}$ \\
& $(6.594)^{* * *}$ & $(6.132)^{* *}$ \\
$\ln g_{i t}^{N}$ & $0.0206^{* *}$ & $0.0187^{* *}$ \\
adjusted $\mathrm{R}^{2}$ & $(2.877)$ & $(2.433)$ \\
\hline
\end{tabular}

Source: Our own calculations based on https://bdl.stat.gov.pl/

Student's t-statistics are given in brackets under the estimates. ${ }^{* * *}$ statistically significant variables were determined at a $1 \%$ level of significance, ${ }^{* *}$ at a $5 \%$ level, ${ }^{*}$ at a $10 \%$ level. In the estimates of the generalized method of moments, instrumental variables are dependent and independent variables delayed by a year. 
All estimated parameters of Eq. (8.8) were statistically noteworthy at least at a significance level of $10 \%$. In the numerical simulations the labor productivity function was adopted; the parameters of which were obtained by averaging the values of the parameters obtained OLS and GMM. This function has the following form:

$$
y_{i t}=1,623 k_{i t}^{0,793} g_{i t}^{0,114}\left(g_{i t}^{N}\right)^{0,0197} .
$$

Function parameters (8.9) can be given the following economic interpretation: Capital-labor ratio (i.e., the internal potential of that province) had the strongest impact on labor productivity in a given voivodeship, the national gravitational effects were much weaker, and the external gravitational effects exerted the least influence. The impact of national effects was more than five times stronger than external effects related to the German economy.

Similar estimates of equation parameters (8.8) for Ukrainian regions are given in Table 8.2.

The estimates of equation parameters (8.8) presented in Table 8.2 for Ukraine show that all independent variables in this equation had a statistically substantial effect on the dependent variable at least at a 5\% significance level.

After averaging the parameter estimates, we get the equation:

$$
y_{i t}=32,346 k_{i t}^{0,341} g_{i t}^{0,0649}\left(g_{i t}^{R}\right)^{0,239}\left(g_{i t}^{P}\right)^{0,0663} \text {. }
$$

The calibrated parameters of the Eq. (8.10) for Ukraine show that the level of labor productivity in the Ukrainian oblasts was most strongly affected

Table 8.2 Estimates of the parameters of Eq. (8.1) for Ukraine

\begin{tabular}{lcc}
\hline Explanatory variables & $O L S$ & $G M M$ \\
\hline $\ln a$ & $3.190^{* * *}$ & $3.763^{* * *}$ \\
& $(11.08)^{* * *}$ & $(12.518)^{* * *}$ \\
$\ln k_{i t}$ & $0.380^{* * *}$ & $0.302^{* * *}$ \\
& $(8.030)^{* *}$ & $(6.154)^{* *}$ \\
$\ln g_{i t}$ & $0.0505^{*}$ & $0.0794^{* *}$ \\
& $(2.060)^{* * *}$ & $(3.153)^{* *}$ \\
$\ln g_{i t}^{P}$ & $0.0464^{* *}$ & $0.0862^{* *}$ \\
$\ln g_{i t}^{R}$ & $(3.23)^{* * *}$ & $(5.607)^{* * *}$ \\
Adjusted $R^{2}$ & $0.211^{* * *}$ & $0.268^{* *}$ \\
& $(9.078)$ & $(10.832)$ \\
\hline
\end{tabular}

Source: Our own calculations based on www.ukrstat.gov.ua

Student's $t$-statistics are given in brackets under the estimates. ${ }^{* * *}$ Statistically significant variables were determined at a $1 \%$ level of significance, ** at a $5 \%$ level, * at a $10 \%$ level. In the estimates of the generalized method of moments, instrumental variables are dependent and independent variables delayed by a year. $g^{P}, g^{R}$ means external gravitational effects flowing (respectively) from Poland and Russia. 
by peripheral capital-labor ratio, followed by gravitational effects flowing from Russia, next from Poland, and finally, by the national gravitational effects. It can be assumed that this is due to the fact that what is happening in eastern Ukraine is more strongly influenced by the economic situation of Russia, and in the west by Poland.

Comparing the calibrated parameters of the labor productivity function (8.8) for Poland (8.9) and Ukraine (8.10), it turns out that in Poland, labor productivity was much more strongly influenced by the amount of capital per employee and national gravitational effects than in Ukraine.

When simulating the trajectory of labor productivity, a system of difference equations was used, analogous to the systems of Eq. (8.6). It looks like this:

$$
\forall i \quad \Delta k_{i}=s_{i} a \frac{k_{i t}^{\alpha+\beta} \prod_{j \neq 1} k_{j t}^{\beta /(\mathrm{N}-1)}}{\bar{d}_{i}^{2 \beta}}\left(g_{i t}^{F}\right)^{\gamma}-\mu_{i} k_{i t-1}
$$

where the subscript $t$ refer to subsequent years, $g_{i t}^{F}$ means foreign gravitational effects, while the other designations as in the case of a system of Eq. (8.6) parameters $\alpha, \beta, \gamma$ were calibrated as in Eqs. (8.9) and (8.10). Using the system of Eq. (8.11), capital-labor ratio was calculated in subsequent regions in subsequent years, which allowed for the calculation of total gravitational effects and levels of labor productivity in regions and years.

\subsection{Simulation of labor productivity trajectories}

\subsubsection{Poland}

It seems that before presenting the results of simulations of labor productivity until 2050, it is necessary, at least briefly, to describe the diversity of labor productivity in the last year in which regional statistical data on this macroeconomic variable are available. Spatial diversity of labor productivity in Poland in 2015 is shown on Map 8.10.

In 2015, the Mazowieckie (145,900 PLN), Wielkopolskie (135,300 PLN) and Dolnośląskie (134,000 PLN) voivodeships were characterized by the highest labor productivity. Labor productivity over 120,000 PLN was also found in the Śląskie (126,500 PLN) and Zachodniopomorskie (122,200 PLN) voivodeships. The lowest levels of labor productivity were found in the Świętokrzyskie (72,500 PLN) and Lubelskie (67,000 PLN) voivodships. Labor productivity below 90 thousand was also found in the following voivodeships, that is, the Podkarpackie (88,600 PLN), Lódzkie (88,300 PLN), Warmińsko-Mazurskie (86,100 PLN) and Podlaskie (82,200 PLN) voivodeships.

Using the gravitational model of economic growth, labor productivity simulations up to 2050 were carried out in eight alternative development scenarios. The scenarios differed in assumptions regarding investment rates, rate of capital depreciation per employee in voivodeships and German GDP growth rates. 


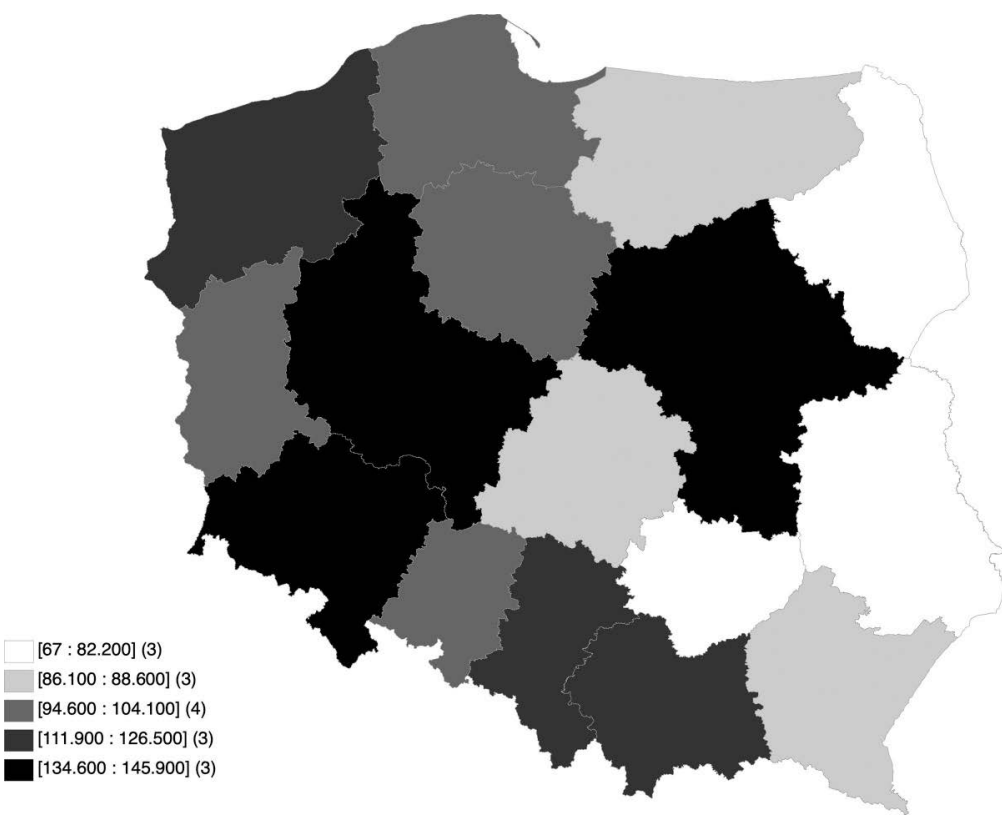

Map 8.10 Diversification of labor productivity in voivodeships in 2015 (thousand PLN, according to 2014 prices).

Source: Our own estimates based on: https://bdl.stat.gov.pl/BDL/start (access: 2019-12-30).

The considered scenarios are as follows (see also Filipowicz 2019):

I In the following years, the investment rate in all voivodeships will be at a level of $20.3 \%$ (equal to the average investment rate in Poland in 2004-2015), and the rate of decrement of capital-labor ratio will be equal to $7 \%$. In addition, Germany's GDP will change at a pace equal to the average dynamics of this variable in 2004-2015.

II In scenario II, the assumption that the same rate of decrement of capital per employee was the same in all voivodeships was rescinded. This variable was dependent on the growth rates of people of working age forecast by the Central Statistical Office (GUS) (i.e., it was assumed that the growth rate of the number of employed will coincide with the growth rate of the number of people of working age forecast by the GUS).

III Scenario III assumes that voivodeships are characterized by constant, over a given timeframe, investment rates as well as capital decrement rates per employee. In addition, it is assumed that the German economy will develop at the same pace as in the years 2009-2015. This scenario differs from scenario I, only under the assumption regarding the GDP growth rate of the German economy. 
IV In the next scenario, it is assumed that investment rates are the same in all voivodeships, the German economy's GDP growth rates are equal to the average for 2009-2015, and the rate of decrement of capital-labor ratio is based on data on the projections of the number of people of working age. Scenario IV differs from scenario II only by an assumption regarding the pace of GDP changes in the German economy.

$\mathrm{V}$ Investment rates in voivodeships will be at a level equal to the average for individual voivodeships from 2004 to 2015. In this scenario (as in scenario I) it is assumed that the capital decrement rates per employee are the same for all voivodeships and that the German economy is growing at an average pace of that of 2004-2015.

VI In the next scenario, it is assumed that not only investment rates are different in individual voivodeships, but also capital decrement rates per employee are different (based on projected GUS data on the number of people of working age). In addition, the scenario under consideration assumes that the German economy will develop economically at a rate equal to the average from 2004 to 2015.

VII Scenario VII adopts the same assumptions as in scenario V with one exception; in other words, it is assumed that the German economy will develop at a slightly faster pace, that is, at a level of the average from 2009 to 2015.

VIII In this scenario, it is assumed that the spatial structure of investment rates is shaped as it was in 2004-2015; in addition, the rate of capital loss per employee (based on forecasts regarding the number of people of working age) also varies and the average GDP growth rate of the German economy is at the average level of 2009-2015.

Table 8.3 presents data on the level of labor productivity in 2015 both in individual voivodeships and groups of voivodeships, as well as the results of numerical simulations of this macroeconomic variable in 2050 in subsequent, previously characterized scenarios. Table 8.3, however, presents the average levels of average annual growth rates of labor productivity in various simulations. ${ }^{6}$

Tables 8.3 and 8.4 draw the following conclusions:

- In scenario I, with the same investment rates and rate of decrement of capital-labor ratio in all voivodeships, the highest (exceeding 650,000 PLN) level of labor productivity in 2050 should be characterized by the Wielkopolskie, Dolnośląskie and Opolskie voivodeships located in the west of Poland, and the Mazowieckie Voivodeship and the Śląskie Voivodeship in central Poland. The group of voivodeships with the lowest level of labor productivity will be composed of the Pomorskie Voivodeship and four out of the five voivodeships of eastern Poland, that is, the Warmińsko-Mazurskie, Podkarpackie, Lubelskie and Podlaskie (see: Map 8.12 in the annex) voivodeships. The fact that the Pomorskie 


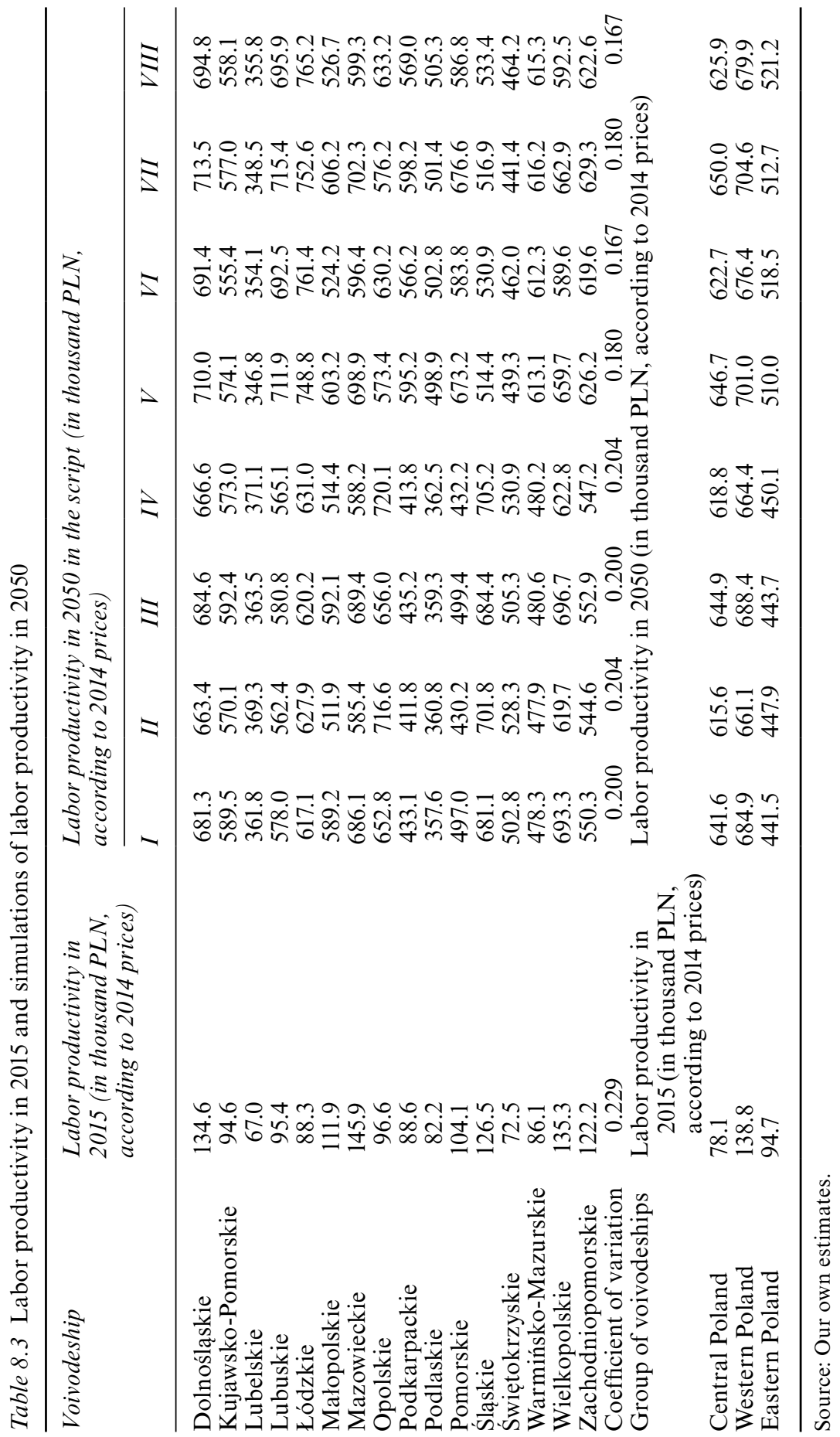


Table 8.4 Average annual growth rates of labor productivity in 2016-2050 in subsequent scenarios $(\%)$

\begin{tabular}{|c|c|c|c|c|c|c|c|c|}
\hline \multirow[t]{2}{*}{ Voivodeship } & \multicolumn{8}{|c|}{ Scenario } \\
\hline & $I$ & $I I$ & $I I I$ & $I V$ & $V$ & $V I$ & $V I I$ & $V I I I$ \\
\hline Dolnoślaskie & 4.8 & 4.7 & 4.8 & 4.7 & 4.9 & 4.8 & 4.9 & 4.8 \\
\hline Kujawsko-Pomorskie & 5.4 & 5.3 & 5.4 & 5.3 & 5.3 & 5.2 & 5.3 & 5.2 \\
\hline Lubelskie & 4.9 & 5.0 & 5.0 & 5.0 & 4.8 & 4.9 & 4.8 & 4.9 \\
\hline Lubuskie & 5.3 & 5.2 & 5.3 & 5.2 & 5.9 & 5.8 & 5.9 & 5.8 \\
\hline Łódzkie & 5.7 & 5.8 & 5.7 & 5.8 & 6.3 & 6.3 & 6.3 & 6.4 \\
\hline Małopolskie & 4.9 & 4.4 & 4.9 & 4.5 & 4.9 & 4.5 & 4.9 & 4.5 \\
\hline Mazowieckie & 4.5 & 4.0 & 4.5 & 4.1 & 4.6 & 4.1 & 4.6 & 4.1 \\
\hline Opolskie & 5.6 & 5.9 & 5.6 & 5.9 & 5.2 & 5.5 & 5.2 & 5.5 \\
\hline Podkarpackie & 4.6 & 4.5 & 4.7 & 4.5 & 5.6 & 5.4 & 5.6 & 5.5 \\
\hline Podlaskie & 4.3 & 4.3 & 4.3 & 4.3 & 5.3 & 5.3 & 5.3 & 5.3 \\
\hline Pomorskie & 4.6 & 4.1 & 4.6 & 4.2 & 5.5 & 5.0 & 5.5 & 5.1 \\
\hline Śląskie & 4.9 & 5.0 & 4.9 & 5.0 & 4.1 & 4.2 & 4.1 & 4.2 \\
\hline Świętokrzyskie & 5.7 & 5.8 & 5.7 & 5.9 & 5.3 & 5.4 & 5.3 & 5.4 \\
\hline Warmińsko-Mazurskie & 5.0 & 5.0 & 5.0 & 5.0 & 5.8 & 5.8 & 5.8 & 5.8 \\
\hline Wielkopolskie & 4.8 & 4.4 & 4.8 & 4.5 & 4.6 & 4.3 & 4.6 & 4.3 \\
\hline Zachodniopomorskie & 4.4 & 4.4 & 4.4 & 4.4 & 4.8 & 4.7 & 4.8 & 4.8 \\
\hline \multicolumn{9}{|l|}{ Group of voivodeships } \\
\hline Central Poland & 5.2 & 5.1 & 5.2 & 5.1 & 5.3 & 5.1 & 5.3 & 5.2 \\
\hline Western Poland & 5.0 & 4.9 & 5.0 & 4.9 & 5.1 & 4.9 & 5.1 & 5.0 \\
\hline Eastern Poland & 5.1 & 5.1 & 5.1 & 5.1 & 5.5 & 5.6 & 5.5 & 5.6 \\
\hline
\end{tabular}

Source: Our own estimates.

Voivodeship (with the very robust Tri-City agglomeration of Gdańsk, Gdynia and Sopot) will be found in this group of voivodeships results from the fact that in this scenario, investment rates in all voivodeships will be at $20.3 \%$, that is, 2 percentage points lower than the investment rate that was recorded in the Pomorskie Voivodeship in 2004-2015.

- In this scenario, those voivodeships located quite close to Warsaw should develop the fastest in 2016-2050, that is, the Lódzkie (5.7\% average annual average), Świętokrzyskie (5.7\%), Kujawsko-Pomorskie $(5.4 \%)$ and Opolskie $(5.6 \%)$ voivodeships. The lowest average annual growth rates of labor productivity should be found in the Mazowieckie (4.5\%), Zachodniopomorskie (4.4\%) and Podlaskie (4.3\%) voivodeships.

- This scenario should also lead to a convergence of labor productivity, as the coefficient of the variability of labor productivity should decrease from 0.229 in 2015 to 0.200 in 2050.

- In Scenario I, labor productivity in the central Poland Voivodeship group should increase from $73.8 \%$ of labor productivity in the Mazowieckie Voivodeship in 2015 to $93.5 \%$ in 2050, in the voivodeships of western Poland from $85.5 \%$ to $99.8 \%$, and in eastern Poland from $53.5 \%$ to $64.3 \%$. 
- In scenario II (the same investment rates, different rate of decrement of capital-labor ratio), the quartile group with the highest labor productivity in 2050 should be composed of the following voivodeships: the Opolskie and Dolnośląskie in western Poland as well as the Łódzkie and Śląskie in central Poland. In contrast, the quartile group with the lowest labor productivity in 2050 coincides with the one obtained in scenario I (Map 8.13 in the annex).

- In the scenario considered here, the highest growth rate of labor productivity should be recorded in the Łódzkie (5.9\%), Opolskie (5.9\%) and Świętokrzyskie $(5.8 \%)$ voivodeships, and the lowest in the Podlaskie (4.3\%), Pomorskie (4.1\%) and Mazowieckie (4.0\%) voivodeships.

- This scenario will also lead to a convergence of labor productivity, as the coefficient of variation of this variable should fall to 0.204 .

- In 2050, the level of labor productivity in the group of voivodeships from western Poland should be $12.9 \%$ higher than in the Mazowieckie Voivodeship, and 5.2\% higher in central Poland, and 13.5\% lower in eastern Poland than in the Mazowieckie Voivodeship. In this scenario, in the group of western Poland voivodeships, the level of labor productivity should be higher than in the Mazowieckie Voivodeship from around 2025, while in central Poland from approximately 2045 (see Figure 8.2 in the Annex).

- In scenario III, which differs from scenario I only by the assumption concerning the growth rate of the German economy (in scenario I a $1.5 \%$ yearly average, in scenario III $1.7 \%$ ), the spatial diversity of labor productivity in 2050 should be very similar to that which was obtained in scenario I (see Map 8.14 in the annex). Labor productivity in voivodeships of central Poland should increase to $93.5 \%$ of the value of this variable in the Mazowieckie Voivodeship, in western Poland to $99.9 \%$ and in eastern Poland to $64.4 \%$. The coefficients of variation of this variable, similar to variant I, should drop to 0.200 .

- In scenario IV, which differs from scenario II only by assuming the growth rate of the German economy, performance simulations were obtained that were very similar to those obtained in scenario II (Map 8.15 in the annex).

- In scenario $\mathrm{V}$, in which it is assumed that the investment rates will be different between voivodeships, the rates of capital deprecation - the same in all voivodeships - and the German economy will develop as on average in 2004-2015; these simulations indicate that the highest level labor productivity in Poland in 2050 should be recorded in the following voivodeships: Łódzkie (almost 750,000 PLN), Lubuskie and Dolnośląskie (about 710,000 PLN) and Mazowieckie (almost 700,000 PLN). At the same time, the lowest level of this macroeconomic variable should be characterized by three voivodeships of eastern Poland: the Podlaskie (approx. 500,000 PLN), Świętokrzyskie (approx. 440,000 PLN) and Lubelskie (just below 350,000 PLN, see Map 8.16 in the annex). 
- In this variant the Lódzkie Voivodeship should develop the fastest (the average annual labor productivity growth rate should be $6.3 \%$ ), followed by the Lubuskie (5.9\%) and Warmińsko-Mazurskie (5.8\%) voivodeships. The lowest rates of growth in labor productivity should be recorded in the Wielkopolskie (4.6\%), Mazowieckie (4.6\%) and Śląskie (4.1\%) voivodeships.

- Labor productivity in the voivodeships of central Poland should increase to $92.5 \%$ of the value of this variable in the Mazowieckie Voivodeship, in western Poland to $100.3 \%$ and in eastern Poland to $73.0 \%$. In this scenario, there would also be a stronger convergence than in scenarios I-IV, as the coefficient of this variation would drop to 0.180 .

- In scenario VI (varied investment rates and the varied rate of decrement of capital-labor ratio), as in scenario $\mathrm{V}$, the highest value of labor productivity in 2050 should be in the Lódzkie Voivodeship (about 760,000 PLN) and three voivodeships in western Poland: Lubuskie (around 690,000 PLN), Dolnośląskie (690,000 PLN) and Opolskie (around 630,000 PLN). At the same time, the lowest level of this macroeconomic variable should be characterized by three voivodeships of eastern Poland: the Podlaskie (approx. 500,000 PLN), Świętokrzyskie (approx. 460,000 PLN) and Lubelskie (just below 350,000 PLN see Map 8.17 in the annex).

- Under these conditions, the highest rates of growth in labor productivity, as in scenario $\mathrm{V}$, should be found in the following voivodeships: Łódzkie (6.3\%), Lubuskie (5.8\%) and Warmińsko-Mazurskie (5.8\%). At the same time, the lowest growth rates of this macroeconomic variable should occur in the following voivodeships: the Mazowieckie (4.1\%), Śląskie $(4.2 \%)$ and Wielkopolskie (4.3\%).

- In the VI scenario, the GDP for people working in the group of western Polish voivodeships should be higher than in the Mazowieckie Voivodeship starting from around 2025, while in central Poland from 2045. In 2050, the labor productivity in western Poland should be higher than the value of this variable in the Mazowieckie Voivodeship by $13.4 \%$, in central Poland by $4.4 \%$, while in eastern Poland by $13.1 \%$.

- In this scenario, a more rapid convergence should occur than in scenario $\mathrm{V}$ (the coefficient of the variation in labor productivity should fall to 0.167$)$.

- Scenarios VII and VIII differ from (respectively) scenarios V and VI only by their assumption about the growth rate of the German economy. Therefore, these scenarios lead to simulations of the spatial differentiation of production per employee analogous to that which occurs in scenarios V and VI.

\subsubsection{Ukraine}

Map 8.11 presents the spatial differentiation of labor productivity in the oblasts of Ukraine in 2017. 


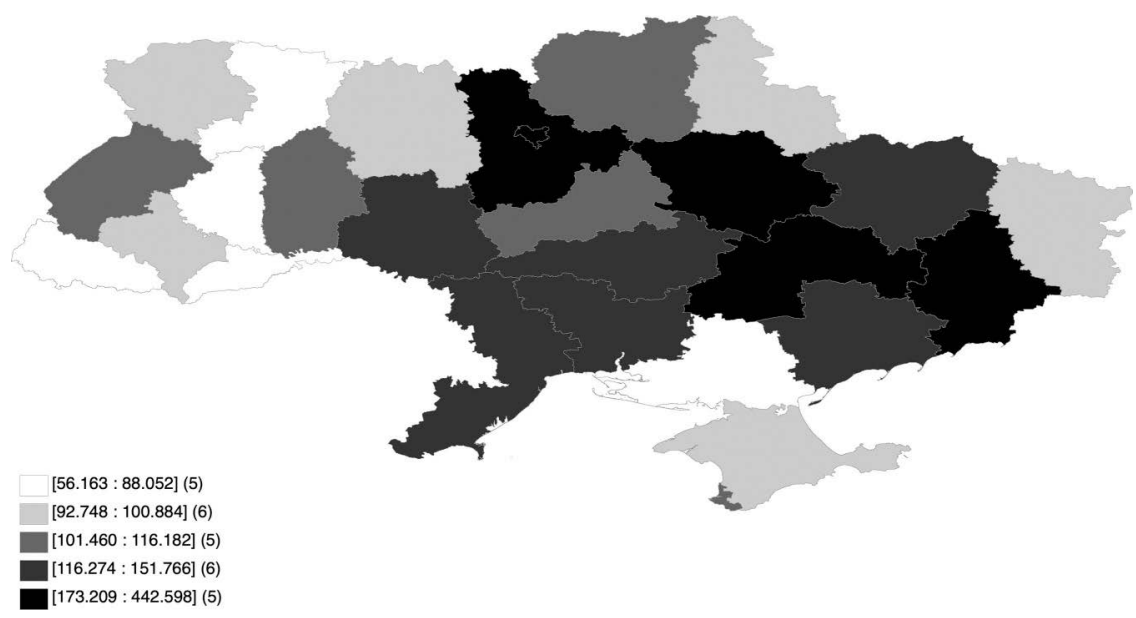

Map 8.11 Diversification of labor productivity in oblasts in 2017 (thousand UAH, according to 2016 prices).

In the case of the ARC and Sevastopol in 2004-2013.

Source: Our own estimates based on: http://www.ukrstat.gov.ua/ (access: 2019-12-30).

We can reach the following conclusions from this map: In 2017, the highest level of labor productivity was recorded in the City of Kyiv (442,600 UAH). Next in order were the Poltava Oblast (193,700 UAH) in central Ukraine, the Kyiv Oblast (182,600 UAH) in northern Ukraine, and the Dnipropetrovsk $(181,200 \mathrm{UAH})$ in central Ukraine and the Donetsk $(173,200$ UAH) Oblast in eastern Ukraine. The quartile group with the lowest value of this feature was composed of the Chernivtsi (56,200 UAH), Zakarpattia (64,900 UAH), Ternopil (80,700 UAH) and Rivne (86,200 UAH) oblasts in the west of Ukraine and the Kherson $(88,100 \mathrm{UAH})$ Oblast in the south of the country. Thus, as in the case of many other macroeconomic variables, labor productivity in the Left-bank Ukraine and on the Black Sea, that is, the Odesa and Mykolayiv oblasts in 2017, was (generally) much higher than in the Right-bank Ukraine (including - in particular - the western Ukrainian oblasts).

Simulations of trajectories of labor productivity in the oblasts of Ukraine in 2018-2050 were carried out using the following eight scenarios:?

I Investment rates in all oblasts will be equal to the average investment rate in Ukraine in the years 2004-2017 (19\%), the Russian and Polish economies will develop as in the years 2004-2017 (i.e., at an annual rate of $2.4 \%$ in Russia and $3.9 \%$ in Poland), the Autonomous Republic of Crimea and Sevastopol would remain under Russian occupation.

II Investment rates in individual oblasts are at the same level as they were in 2004-2017, other assumptions as in scenario I. 
III Investment rates in all regions are 19\%, the Russian and Polish economies are developing as in scenarios I-II, the Crimean Peninsula is returned to Ukraine.

IV Investment rates vary in subsequent circuits, other assumptions as in scenario III.

$\mathrm{V}$ The same investment rates in all regions, the Russian economy is growing at an average annual rate of $1 \%$, Poland 3.3\%, the Autonomous Republic of Crimea and Sevastopol remain under Russian occupation.

VI Different investment rates in subsequent circuits, other assumptions as in scenario $\mathrm{V}$.

VII The same investment rates in all oblasts, the Russian and Polish economies are developing as in scenario VI, the Crimean Peninsula is returned to Ukraine.

VIII Different investment rates in subsequent regions, the Russian and Polish economies are developing as in the assumptions V-VII, the Autonomous Republic of Crimea and Sevastopol are returned to Ukraine.

Table 8.5 presents data on the level of labor productivity in 2017 both in individual oblasts and groups of oblasts as well as the results of numerical simulations of this macroeconomic variable in 2050 in subsequent, previously characterized scenarios. Table 8.6, however, presents the average levels of the average annual growth rates of labor productivity in various simulations in oblasts and groups of oblasts.

Tables 8.5 and 8.6 draw the following conclusions:

- In scenario I, the highest level of labor productivity in 2050 should be in the Sumy Oblast (about 400,000 UAH), Kyiv (over 370,000 UAH) and the Chernihiv Oblast (over 310,000 UAH) in the north of Ukraine, the Kharkiv Oblast (around 360,000 UAH) in the east and the Poltava Oblast (around 350,000 UAH) in central Ukraine. The lowest value of this feature should be found in the west of the country, in the Zakarpattia Oblast (about 120,000 UAH), and the Chernivtsi (almost 160,000 UAH), Ivano-Frankivsk (over 160,000 UAH) and Lviv (over 170,000 UAH) oblasts, and in the Odesa Oblast, located on the Black Sea (almost 180,000 UAH, see also Map 8.20 in the annex).

- In this scenario, the highest, exceeding $3 \%$, average annual growth rates should be found in the Sumy Oblast (northern Ukraine, 4.3\%), and the Chernihiv (northern Ukraine, 3.5\%), Kharkiv (eastern Ukraine, 3.3\%) and Chernivtsi (western Ukraine, 3.2\%) oblasts. In Kyiv, the average annual growth rates should be negative $(-0.5 \%)$, while in the Odesa (southern Ukraine), Donetsk (eastern Ukraine) and Lviv (western Ukraine) oblasts, they should not exceed $1.5 \%$. The negative projected growth rates in Kyiv result from the fact that scenario I assumes a $19 \%$ investment rate in all oblasts, while in Kyiv in 2004-2017 this rate was 23.8\%. 


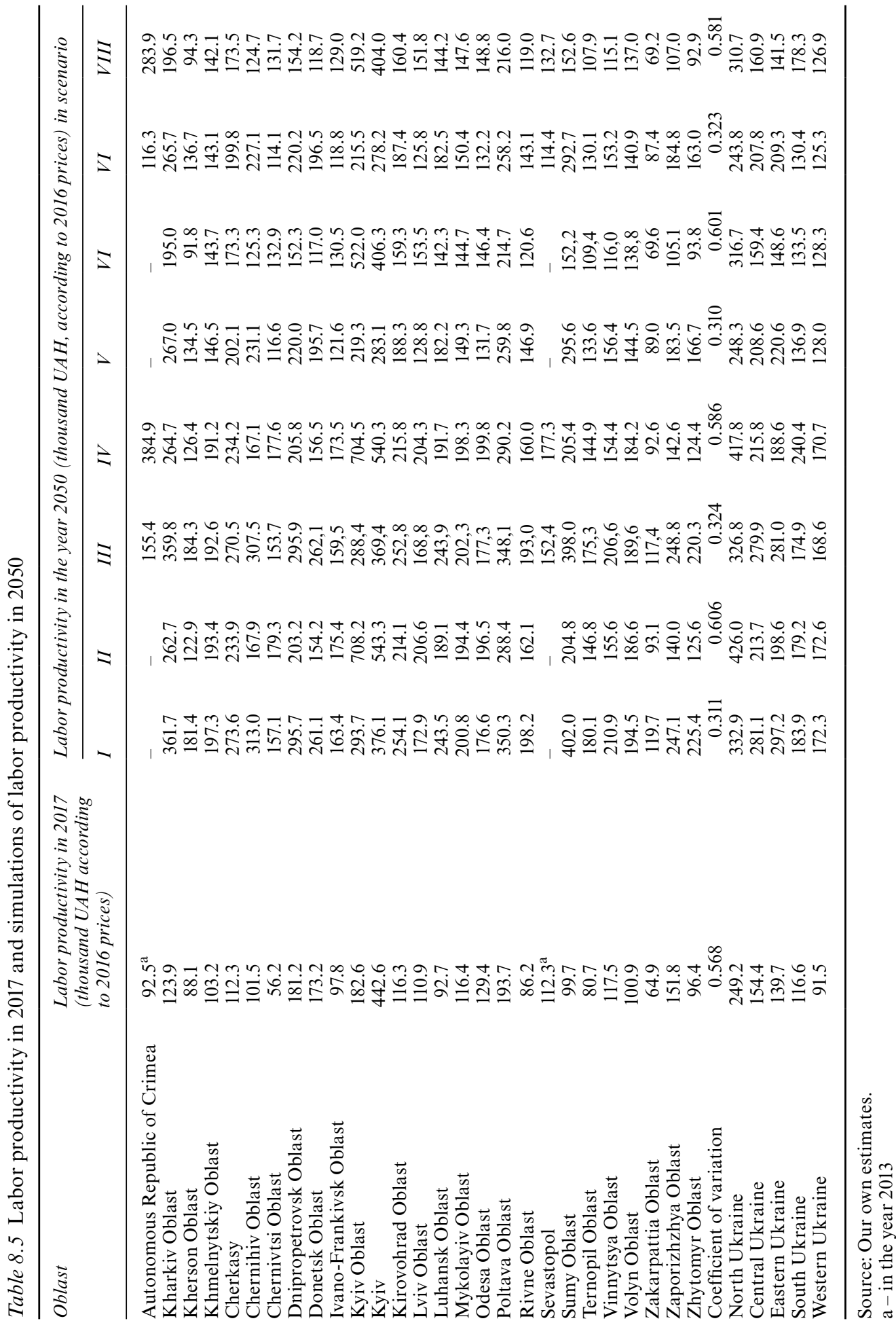


Table 8.6 Average annual growth rates of labor productivity in 2018-2050 in subsequent scenarios $(\%)$

\begin{tabular}{|c|c|c|c|c|c|c|c|c|}
\hline Oblast & $I$ & $I I$ & $I I I$ & $I V$ & $V$ & $V I$ & $V I$ & $V I I I$ \\
\hline Autonomous Republic of Crimea & - & - & 1.6 & 4.4 & - & - & 0.7 & 3.5 \\
\hline Kharkiv Oblast & 3.3 & 2.3 & 3.3 & 2.3 & 2.4 & 1.4 & 2.3 & 1.4 \\
\hline Kherson Oblast & 2.2 & 1.0 & 2.3 & 1.1 & 1.3 & 0.1 & 1.3 & 0.2 \\
\hline Khmelnytskiy Oblast & 2.0 & 1.9 & 1.9 & 1.9 & 1.1 & 1.0 & 1.0 & 1.0 \\
\hline Cherkasy & 2.7 & 2.2 & 2.7 & 2.3 & 1.8 & 1.3 & 1.8 & 1.3 \\
\hline Chernihiv Oblast & 3.5 & 1.5 & 3.4 & 1.5 & 2.5 & 0.6 & 2.5 & 0.6 \\
\hline Chernivtsi Oblast & 3.2 & 3.6 & 3.1 & 3.6 & 2.2 & 2.6 & 2.2 & 2.6 \\
\hline Dnipropetrovsk Oblast & 1.5 & 0.3 & 1.5 & 0.4 & 0.6 & -0.5 & 0.6 & -0.5 \\
\hline Donetsk Oblast & 1.3 & -0.4 & 1.3 & -0.3 & 0.4 & -1.2 & 0.4 & -1.1 \\
\hline Ivano-Frankivsk Oblast & 1.6 & 1.8 & 1.5 & 1.8 & 0.7 & 0.9 & 0.6 & 0.8 \\
\hline Kyiv Oblast & 1.5 & 4.2 & 1.4 & 4.2 & 0.6 & 3.2 & 0.5 & 3.2 \\
\hline Kyiv & -0.5 & 0.6 & -0.5 & 0.6 & -1.3 & -0.3 & -1.4 & -0.3 \\
\hline Kirovohrad Oblast & 2.4 & 1.9 & 2.4 & 1.9 & 1.5 & 1.0 & 1.5 & 1.0 \\
\hline Lviv Oblast & 1.4 & 1.9 & 1.3 & 1.9 & 0.5 & 1.0 & 0.4 & 1.0 \\
\hline Luhansk Oblast & 3.0 & 2.2 & 3.0 & 2.2 & 2.1 & 1.3 & 2.1 & 1.3 \\
\hline Mykolayiv Oblast & 1.7 & 1.6 & 1.7 & 1.6 & 0.8 & 0.7 & 0.8 & 0.7 \\
\hline Odesa Oblast & 0.9 & 1.3 & 1.0 & 1.3 & 0.1 & 0.4 & 0.1 & 0.4 \\
\hline Poltava Oblast & 1.8 & 1.2 & 1.8 & 1.2 & 0.9 & 0.3 & 0.9 & 0.3 \\
\hline Rivne Oblast & 2.6 & 1.9 & 2.5 & 1.9 & 1.6 & 1.0 & 1.5 & 1.0 \\
\hline Sevastopol & - & - & 0.9 & 1.4 & - & - & 0.1 & 0.5 \\
\hline Sumy Oblast & 4.3 & 2.2 & 4.3 & 2.2 & 3.3 & 1.3 & 3.3 & 1.3 \\
\hline Ternopil Oblast & 2.5 & 1.8 & 2.4 & 1.8 & 1.5 & 0.9 & 1.5 & 0.9 \\
\hline Vinnytsya Oblast & 1.8 & 0.9 & 1.7 & 0.8 & 0.9 & 0.0 & 0.8 & -0.1 \\
\hline Volyn Oblast & 2.0 & 1.9 & 1.9 & 1.8 & 1.1 & 1.0 & 1.0 & 0.9 \\
\hline Zakarpattia Oblast & 1.9 & 1.1 & 1.8 & 1.1 & 1.0 & 0.2 & 0.9 & 0.2 \\
\hline Zaporizhzhya Oblast & 1.5 & -0.2 & 1.5 & -0.2 & 0.6 & -1.1 & 0.6 & -1.1 \\
\hline Zhytomyr Oblast & 2.6 & 0.8 & 2.5 & 0.8 & 1.7 & -0.1 & 1.6 & -0.1 \\
\hline Group of oblasts & $I$ & $I I$ & $I I I$ & $I V$ & $V$ & $V I$ & $V I I$ & $V I I I$ \\
\hline North Ukraine & 0.9 & 1.6 & 0.8 & 1.6 & 0.0 & 0.7 & -0.1 & 0.7 \\
\hline Central Ukraine & 1.8 & 1.0 & 1.8 & 1.0 & 0.9 & 0.1 & 0.9 & 0.1 \\
\hline Eastern Ukraine & 2.3 & 1.1 & 2.1 & 0.9 & 1.4 & 0.2 & 1.2 & 0.0 \\
\hline South Ukraine & 1.4 & 1.3 & 1.2 & 2.2 & 0.5 & 0.4 & 0.3 & 1.3 \\
\hline Western Ukraine & 1.9 & 1.9 & 1.9 & 1.9 & 1.0 & 1.0 & 1.0 & 1.0 \\
\hline
\end{tabular}

Source: Our own estimates.

- As a result of these changes, the relation of labor productivity in the oblasts of central Ukraine in comparison to northern Ukraine should increase from $62.0 \%$ to $84.4 \%$, in eastern Ukraine from $56.1 \%$ to $89.3 \%$, in southern Ukraine from $46.8 \%$ to $55.2 \%$ and in western Ukraine from $36.7 \%$ to $51.8 \%$. As the coefficient of variability of labor productivity also drops from 0.568 in 2017 to 0.311 in 2050, (with the same investment rates in all regions) in Ukraine there should be a process of spatial convergence of labor productivity (see also Figure 8.9 in the Annex).

- In the second scenario (varying investment rates in the oblasts, the Crimean peninsula still under Russian occupation), the highest level of 
labor productivity in 2050 should be recorded in the Kyiv Oblast (northern Ukraine, over 700,000 UAH), then in the City of Kyiv (over 540,000 UAH), in the Poltava (almost 290,000 UAH) and Cherkasy (over 230,000 UAH) oblasts in central Ukraine and the Kharkiv (around 260,000 UAH) Oblast in the east of Ukraine. The lowest value of this variable should be found in the Zakarpattia (over 90,000 UAH) and Ternopil oblasts (nearly 150,000 UAH) in the west of the country, in the Kherson (around 120,000 UAH) Oblast in the south, and the Zhytomyr (almost 130,000 UAH) Oblast in north and the Zaporizhzhya (about 140,000 UAH) Oblast in the east of Ukraine (see Map 8.21).

- In this variant, the Kyiv Oblast (4.2\%) in northern Ukraine and the Chernivtsi (3.6\%) Oblast in western Ukraine should definitely have the highest average annual productivity growth rates. In the Donetsk and Zaporizhzhya oblasts (in the east of Ukraine), the average annual labor productivity growth rates may be negative $(-0.4 \%$ and $-0.2 \%$, respectively), while in the Dnipropetrovsk Oblast (central Ukraine), in Kyiv and in the Zhytomyr (northern Ukraine) and Vinnytsya (central Ukraine) oblasts, these growth rates will be lower than $1 \%$.

- In this scenario, labor productivity in central Ukraine should fall to around $50 \%$ of this variable in northern Ukraine, in eastern Ukraine to $46.6 \%$, in southern Ukraine to $42.1 \%$, while in the west to $40.5 \%$ of the labor productivity in the northern Ukrainian oblasts. Moreover, in this scenario, the oblasts of southern Ukraine should outperform the east and the center of Ukraine in terms of labor productivity between 2030 and 2035.

- As in this scenario the coefficient of the variability of labor productivity will increase from 0.568 to 0.606 , scenario II (as opposed to scenario I) will lead to a divergence of labor productivity. This divergence will most strongly affect the most industrialized oblasts of eastern Ukraine, in which investment rates (also in the highly developed heavy and mining industries) were low.

- In scenario III (in which we assume the same investment rates in all oblasts, but we also assume that the Autonomous Republic of Crimea and Sevastopol have been returned to Ukraine), the highest labor productivity in 2050 should be in the Sumy (northern Ukraine approx. 400,000 UAH), Kyiv (almost 370,000 UAH) and Kharkiv oblasts (eastern Ukraine, almost 360,000 UAH), and in the Poltava (central Ukraine, almost 350,000 UAH) and Chernihiv oblasts (northern Ukraine, almost $310,000 \mathrm{UAH})$. The lowest labor productivity should then be recorded by the Zakarpattia Oblast (less than 120,000 UAH) in the west, Sevastopol and the Autonomous Republic of Crimea in the south, as well as the Chernivtsi and Ivano-Frankivsk oblasts in the west (approx. 150$160,000 \mathrm{UAH}$, see Map 8.22 in the annex).

- In Scenario III, labor productivity should increase the fastest in the Sumy Oblast (4.3\%) in northern Ukraine, then in the Chernihiv oblasts 
in the north, then the Kharkiv and Luhansk oblasts in the east and in Chernivtsi Oblast in the west (an average annual increase in labor productivity of approx. 3-3.5\%). In Kyiv, as in option I, the growth rate of production per employee may be, at this time, negative (around $-0.5 \%$ ), while in Sevastopol and the Odesa Oblast (southern Ukraine) no more than $1 \%$.

- In scenario III, labor productivity relationships in the oblasts of central, southern, eastern and western Ukraine (compared to the value of this variable in northern Ukraine) would be at levels similar to those obtained in Option I. Also, the coefficient of the variation in labor productivity would fall to 0.324 , and therefore there would be a convergence of the spatial differentiation of labor productivity in Ukraine.

- In Scenario IV, we differentiate investment rates of the oblasts, maintaining the assumption that the Crimean Peninsula has been returned to Ukraine. In this scenario, as in scenario II, the Kyiv Oblast in the north of Ukraine (about 700,000 UAH) should have the highest labor productivity in 2050. Next in line should be the City of Kyiv (about 540,000 UAH), the Autonomous Republic of Crimea (about 390,000 UAH) in the south and the Poltava region (about 290,000 UAH) in central Ukraine. The group of regions with the lowest labor productivity (below 150,000 UAH) should be composed of the following oblasts: Zakarpattia and Ternopil in the west of Ukraine, Zhytomyr in the north, Kherson in the south and Zaporizhzhya in the east (see Map 8.23 in the annex).

- In this scenario, the Autonomous Republic of Crimea (4.4\%) as well as the Kyiv (northern Ukraine, $4.2 \%$ ) and Chernivtsi (western Ukraine $4.6 \%$ ) oblasts should enjoy the highest rates of labor productivity growth.

- As a result of these changes, labor productivity in central Ukraine in 2050 should constitute $51.7 \%$ of the value of this variable in northern Ukraine, eastern Ukraine only $45.1 \%$, southern $57.5 \%$ and western Ukraine 40.9\%. Moreover, in this scenario between 2030 and 2035, the southern oblasts of Ukraine should overtake, in terms of labor productivity, the central and eastern oblasts of this country, while the currently poorest oblasts, that is, those of western Ukraine, will have results approximating the eastern oblasts, which are presently the most developed industrially.

- In the scenario considered here, the coefficient of variation in labor productivity will increase from 0.568 to 0.586 , which means that the divergence of this macroeconomic variable will slightly increase.

- Scenarios V-VIII are identical to scenarios I-IV when it comes to the differentiation or non-differentiation of investment rates and further Russian occupation or the return of Crimea to Ukraine. However, they differ in their assumptions about the growth rates of the Russian and Polish economies. We assume here that Russia's economic growth will slow down from $2.4 \%$ to $1.1 \%$, while in Poland from $3.9 \%$ to $3.3 \%$. 
- This modification of the assumption about the slowdown in the economic growth rate of Ukraine's most important neighbors will not affect the simulations of spatial differentiation of labor productivity in this country (compared to the simulations obtained in Scenarios I-IV). However, the economic slowdown in Russia and Poland may lead to the fact that the level of labor productivity in Ukrainian oblasts will be about $25 \%$ lower than what could have been achieved, with a more rapid development of the Polish and Russian economies.

- Comparing the results of the simulation of labor productivity in Poland and Ukraine, we note that the Polish regions should develop much faster than the Ukrainian ones. This means that without deep, thorough, market-oriented reforms and further integration of Ukraine (mainly) with the EU countries, development disparities between this country and Poland and other EU countries may be constantly increasing.

\subsection{Annex}

Simulations of spatial differentiation of labor productivity in 2050 in voivodeships and oblasts and trajectories of simulations of labor productivity up to 2050 in voivodeship and oblast groups.

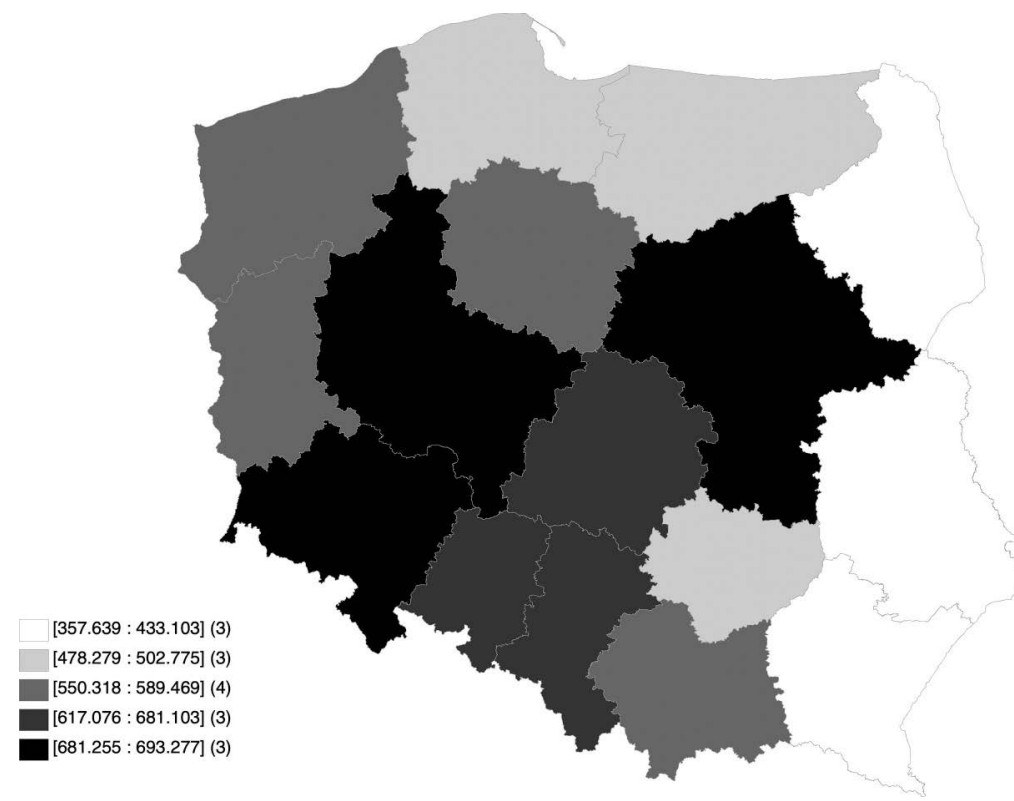

Map 8.12 Diversification of labor productivity in voivodeships in scenario I (thousand PLN, according to 2014 prices).

Source: Our own estimates. 


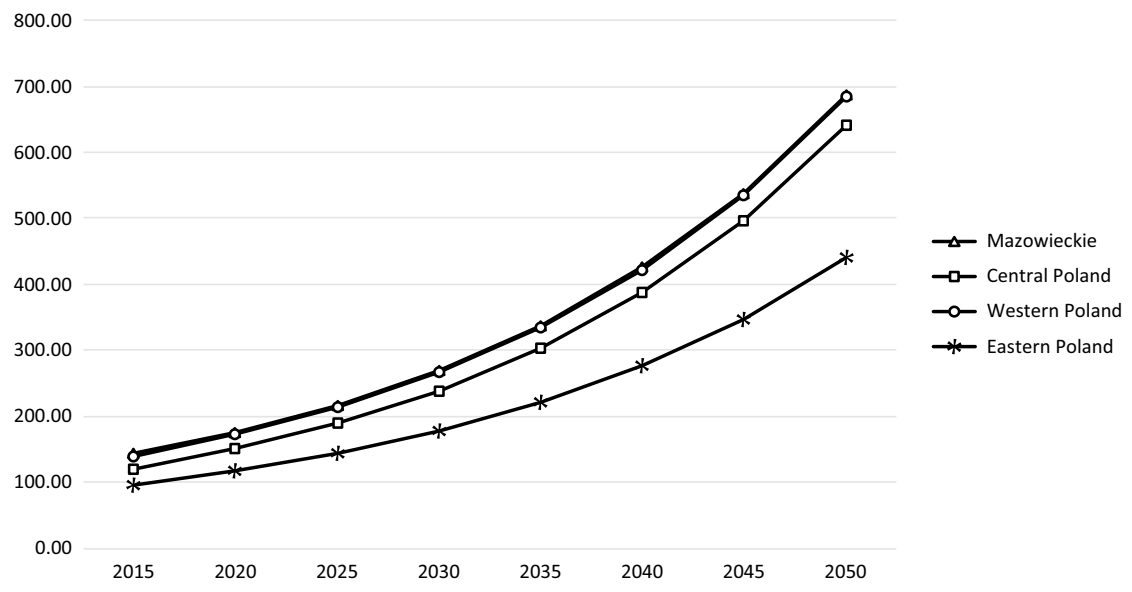

Figure 8.1 Simulation of trajectories of labor productivity in groups of voivodeships in scenario I (thousand PLN, according to 2014 prices).

Source: Our own estimates.

[360.799: 411.822] (3)

[430.167:511.899] (3)

$[528.293: 570.149](4)$

[585.354:627.893] (3)

[663.396: 716.576] (3)

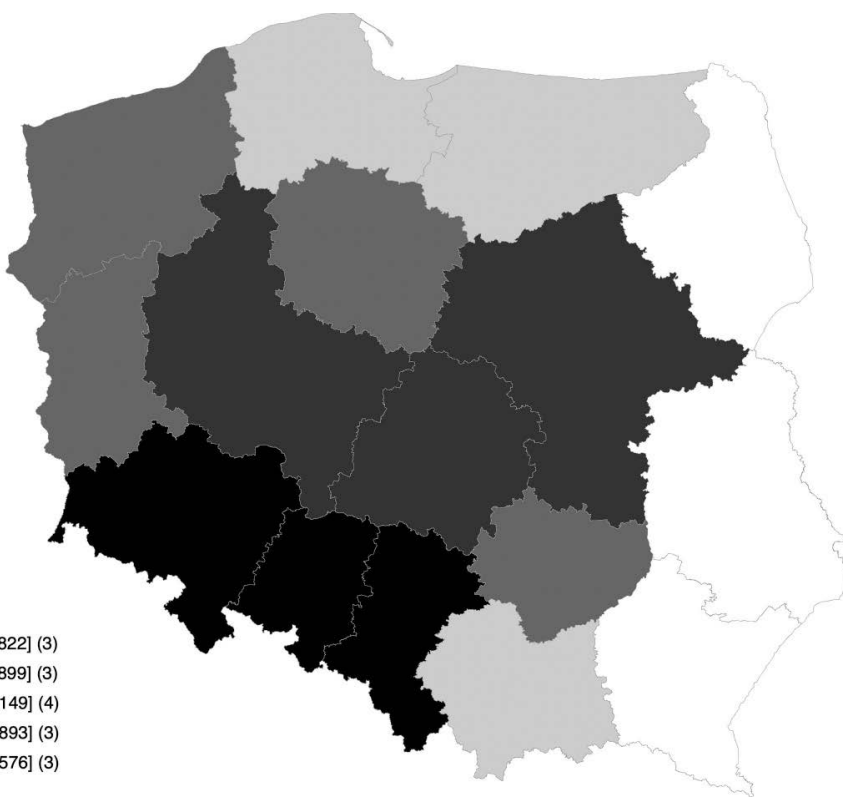

Map 8.13 Labor productivity in 2050 in voivodeships in scenario II (thousand PLN, according to 2014 prices).

Source: Our own estimates. 


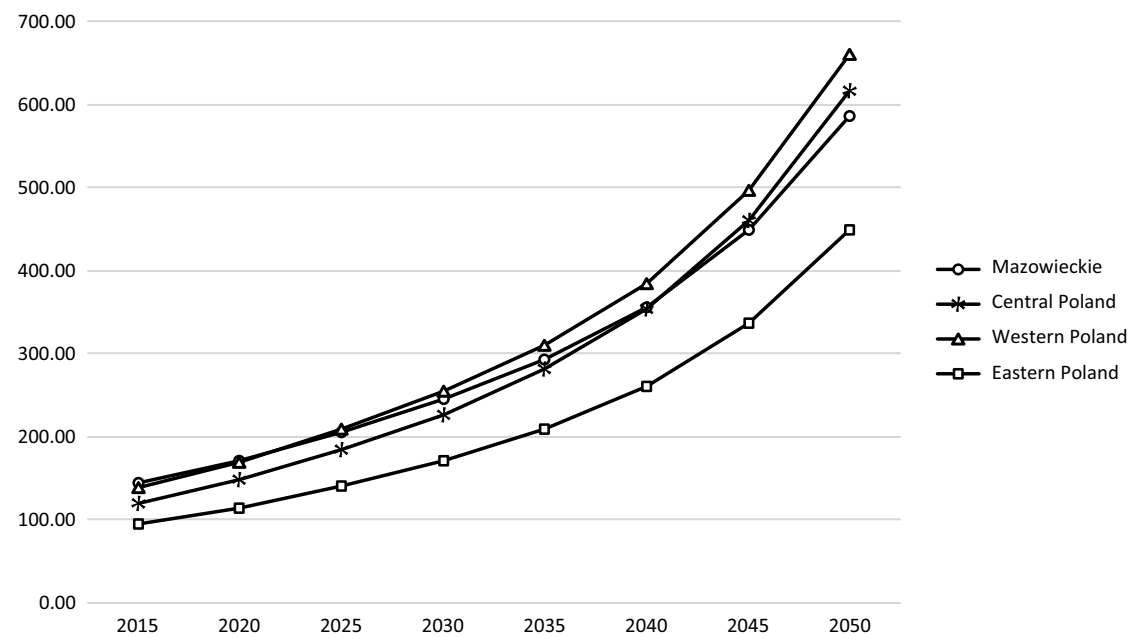

Figure 8.2 Simulation of trajectories of labor productivity in groups of voivodeships in scenario II (thousand PLN, according to 2014 prices).

Source: Our own estimates.

[359.314: 435.170] (3) [480.593:505.269] (3)

[552.918: 592.376] (4)

[620.152: 684.439] (3)

[684.578 : 696.663] (3)

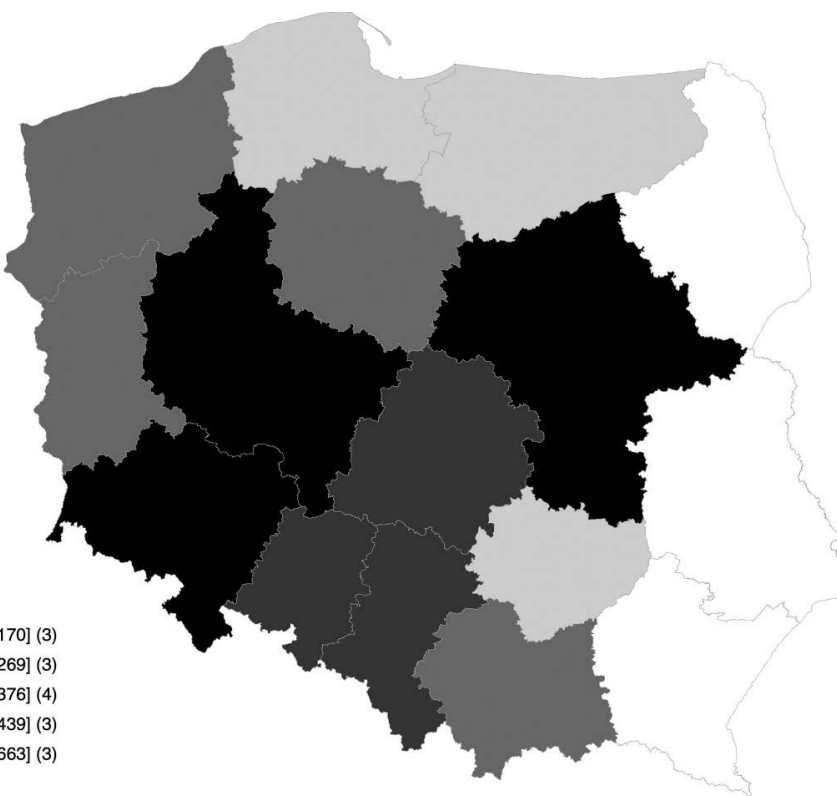

Map 8.14 Labor productivity in 2050 in voivodeships in scenario III (thousand PLN, according to 2014 prices).

Source: Our own estimates. 
184 Svitlana Chugaievska et al.

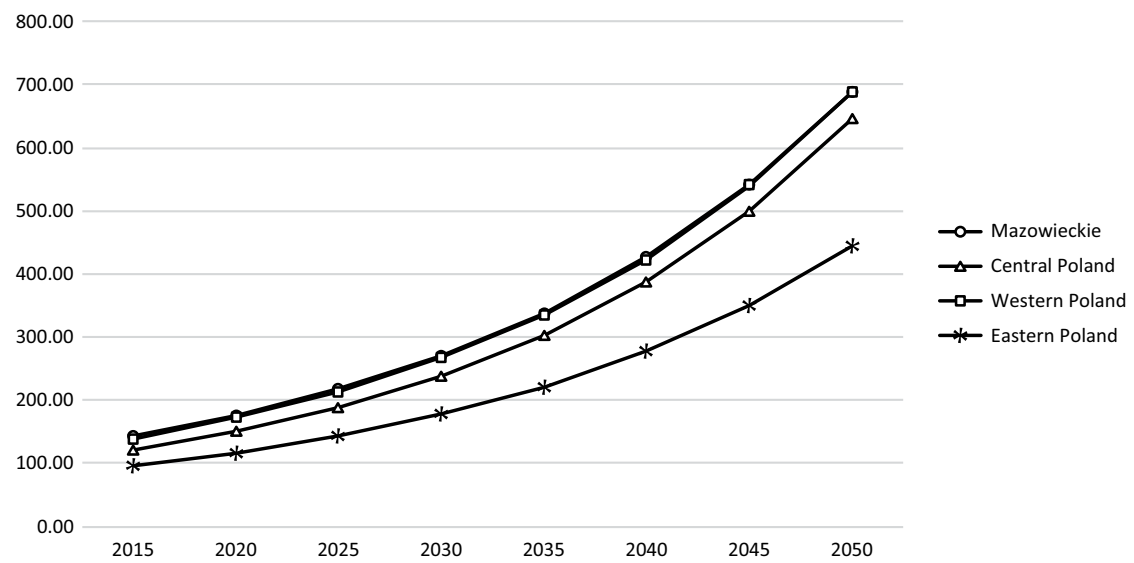

Figure 8.3 Simulation of trajectories of labor productivity in groups of voivodeships in scenario III (thousand PLN, according to 2014 prices).

Source: Our own estimates.

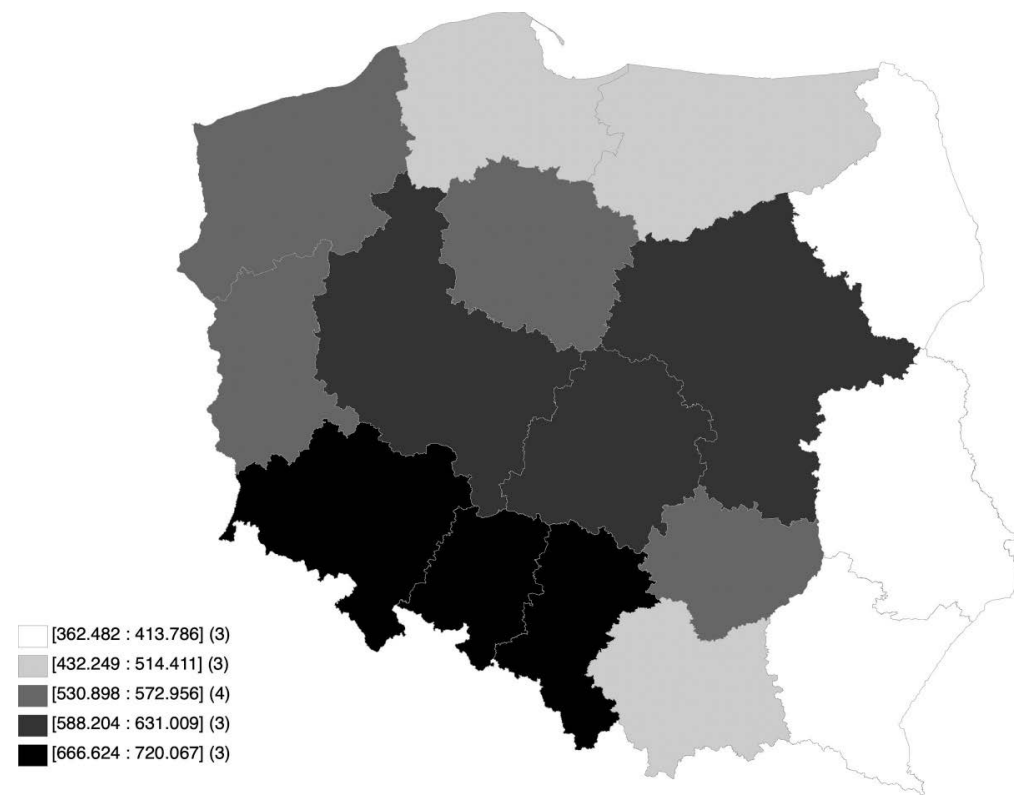

Map 8.15 Labor productivity in 2050 in voivodeships in scenario IV (thousand PLN, according to 2014 prices).

Source: Our own estimates. 


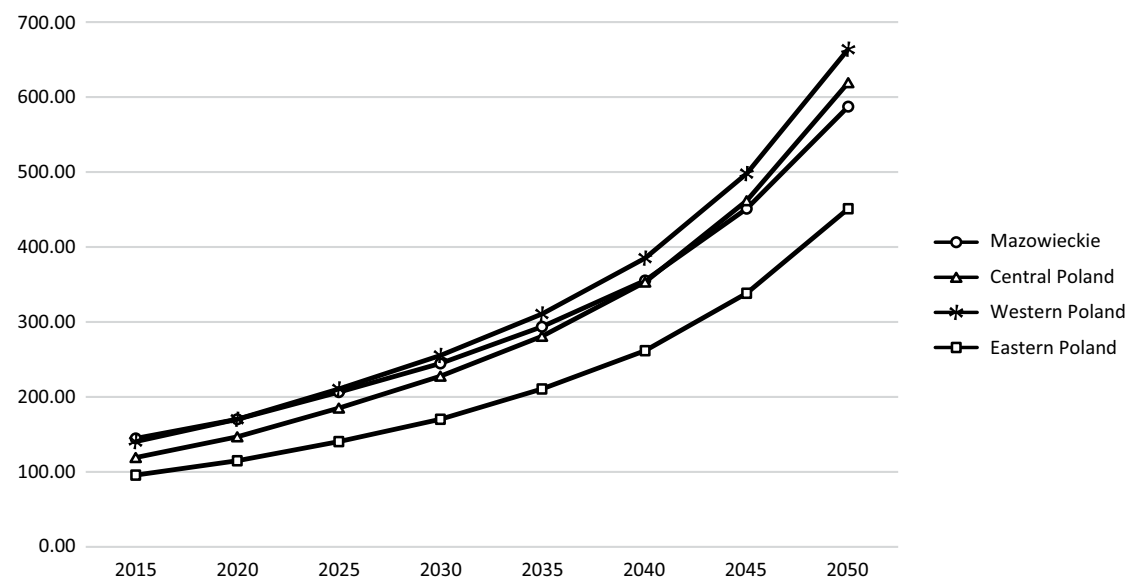

Figure 8.4 Simulation of trajectories of labor productivity in groups of voivodeships in scenario IV (thousand PLN, according to 2014 prices).

Source: Our own estimates.

[346.820 : 498.914] (3)

[514.445: 574.130] (3)

[595.199 : 626.244] (4)

[659.684 : 698.906] (3)

[710.044: 748.804] (3)

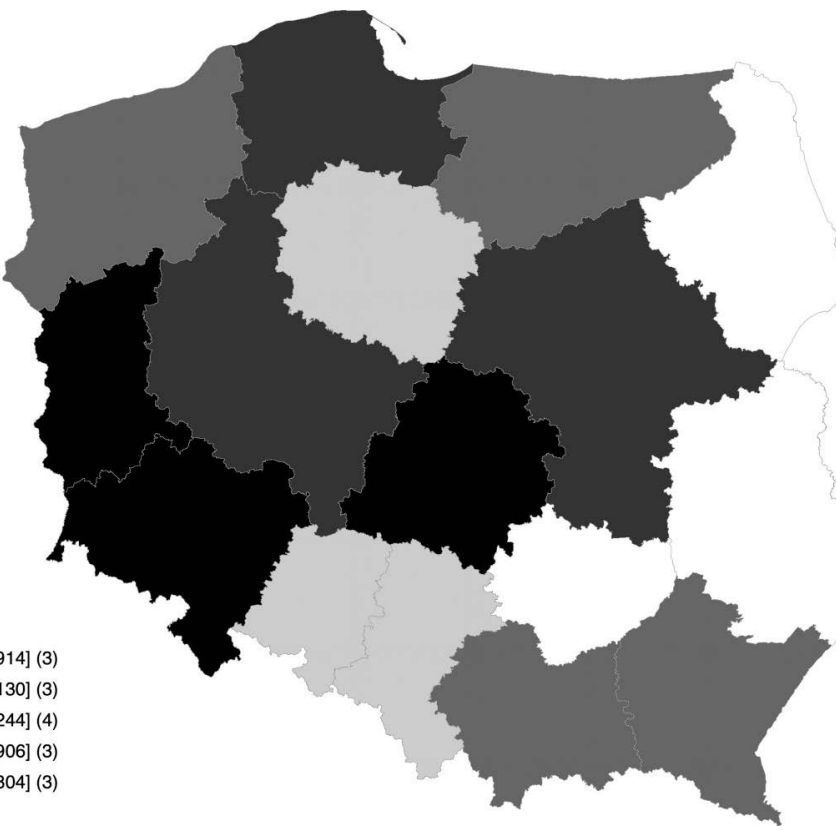

Map 8.16 Labor productivity in 2050 in voivodeships in scenario V (thousand PLN, according to 2014 prices).

Source: Our own estimates. 


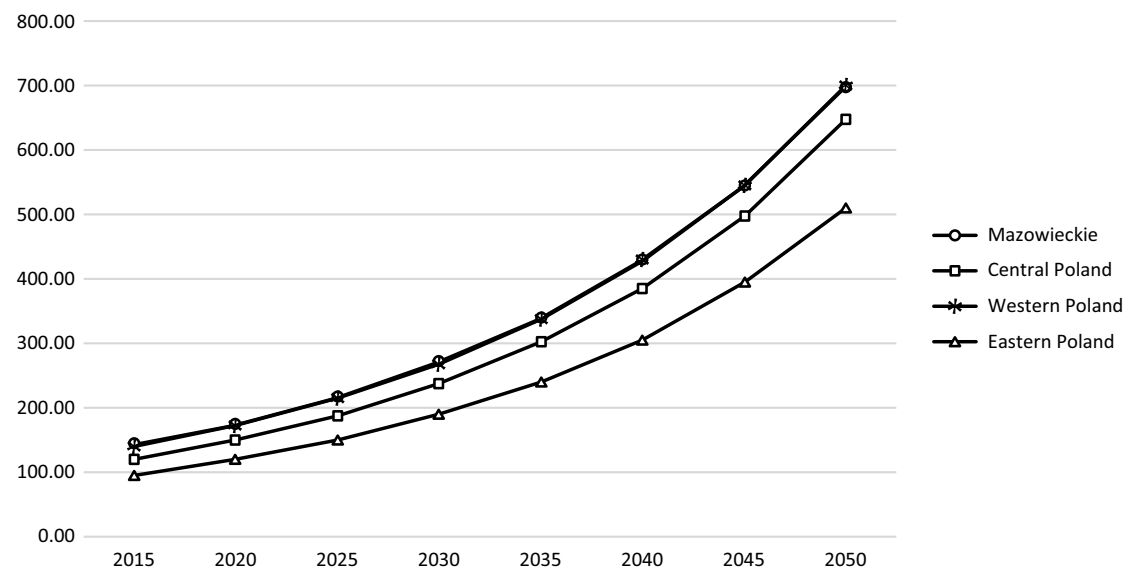

Figure 8.5 Simulation of trajectories of labor productivity in groups of voivodeships in scenario V (thousand PLN, according to 2014 prices).

Source: Our own estimates.

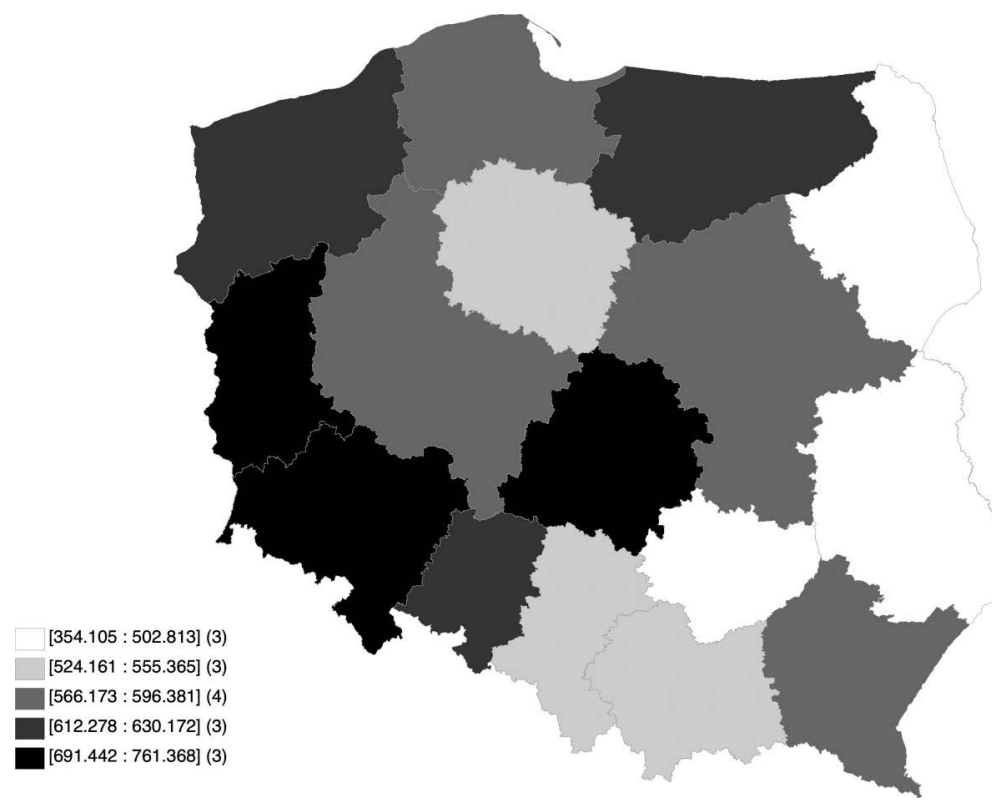

Map 8.17 Labor productivity in 2050 in voivodeships in scenario VI (thousand PLN, according to 2014 prices).

Source: Our own estimates. 
800.00

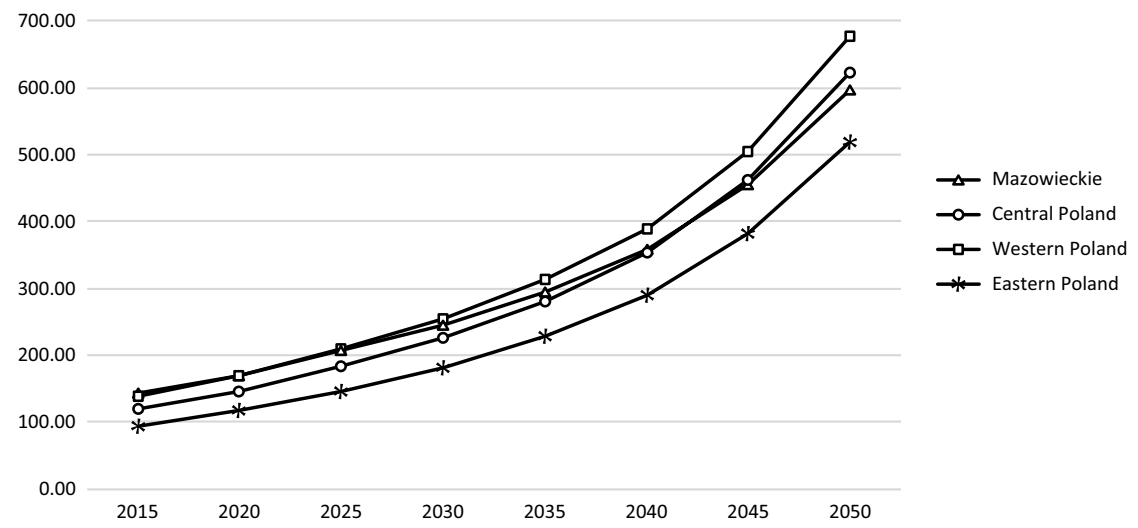

Figure 8.6 Simulation of trajectories of labor productivity in groups of voivodeships in scenario VI (thousand PLN, according to 2014 prices).

Source: Our own estimates.

[348.484:501.365] (3)

[516.876: 576.959] (3)

$[598.170: 629.263](4)$

$[662.892: 702.311](3)$

[713.535: 752.636] (3)

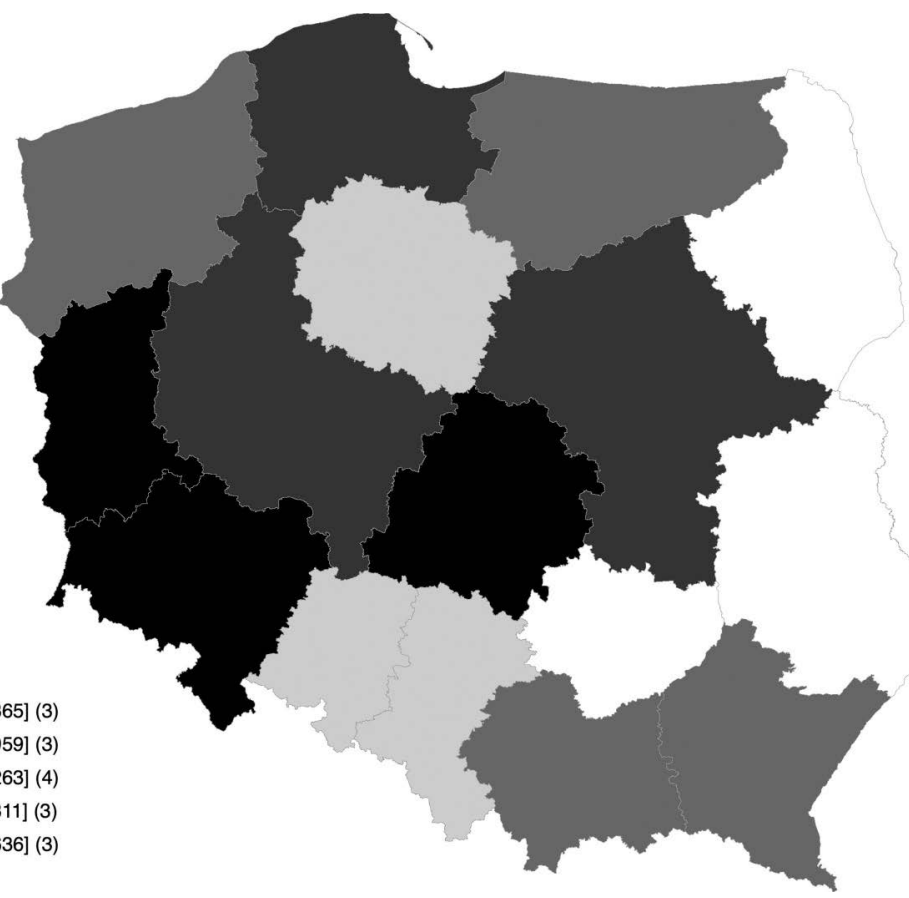

Map 8.18 Labor productivity in 2050 in voivodeships in scenario VII (thousand PLN, according to 2014 prices).

Source: Our own estimates. 


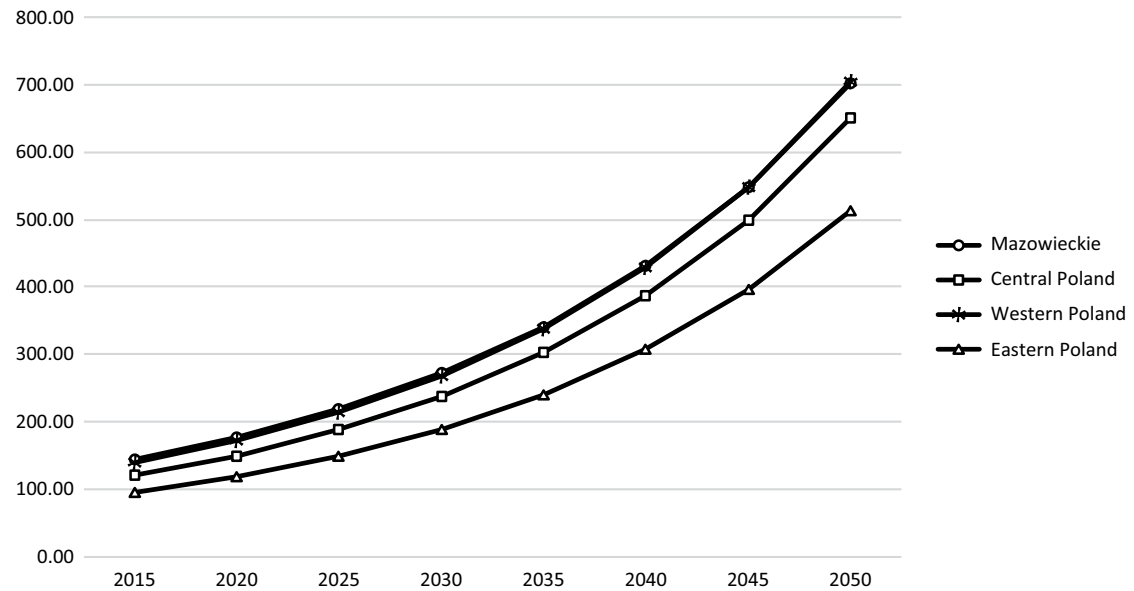

Figure 8.7 Simulation of trajectories of labor productivity in groups of voivodeships in scenario VII (thousand PLN, according to 2014 prices).

Source: Our own estimates.

[355.796: 505.273] (3)

[526.748: 558.097] (3)

[568.995 : 599.299] (4)

[615.333: 633.197] (3)

$[694.833: 765.247](3)$

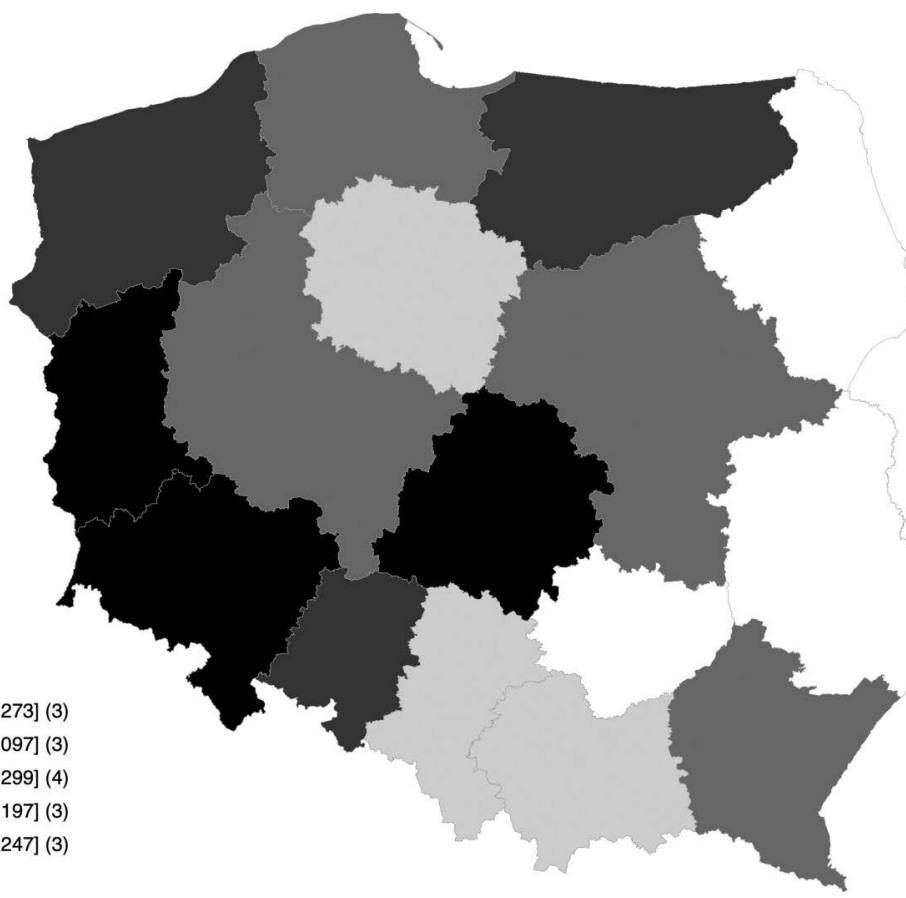

Map 8.19 Labor productivity in 2050 in voivodeships in scenario VIII (thousand PLN, according to 2014 prices).

Source: Our own estimates. 


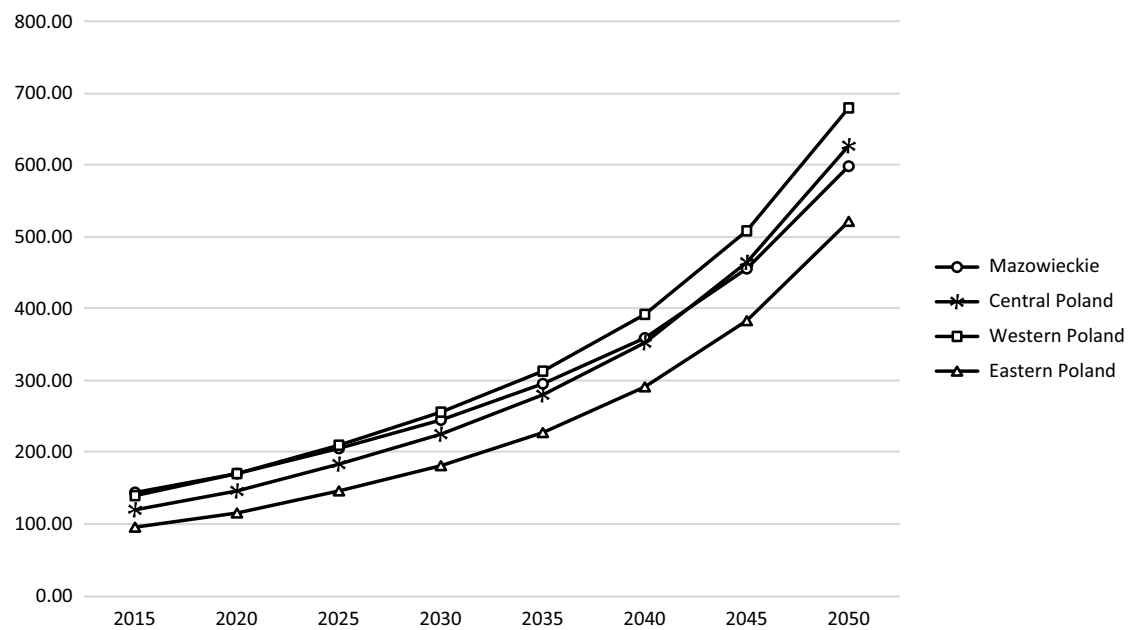

Figure 8.8 Simulation of trajectories of labor productivity in groups of voivodeships in scenario VIII (thousand PLN, according to 2014 prices).

Source: Our own estimates.

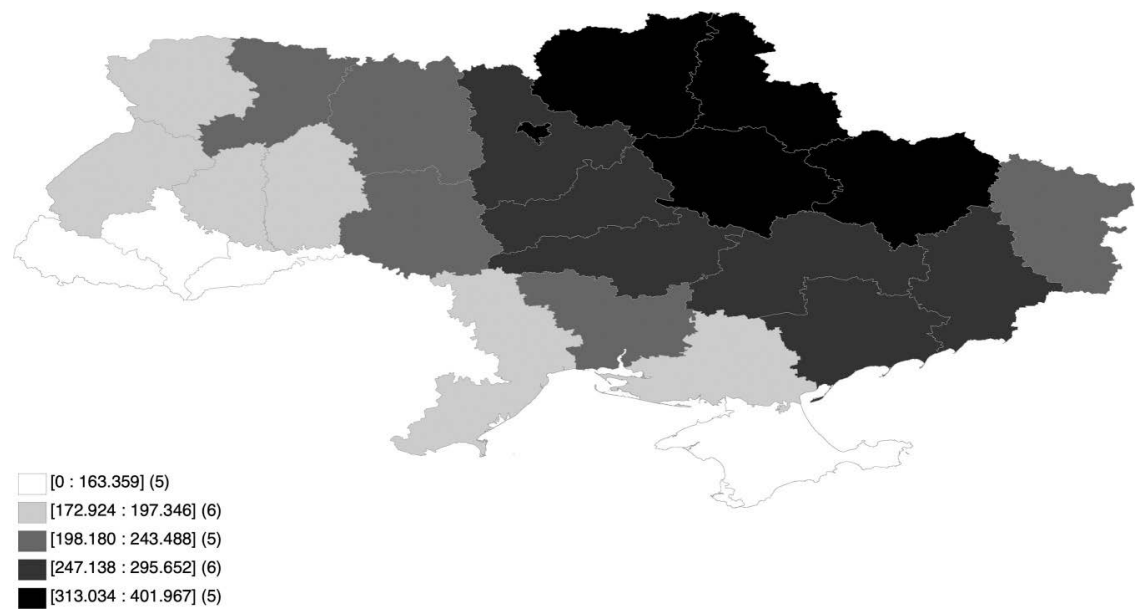

Map 8.20 Diversification of labor productivity in oblasts in scenario I (thousand UAH, according to 2016 prices).

Source: Our own estimates. 


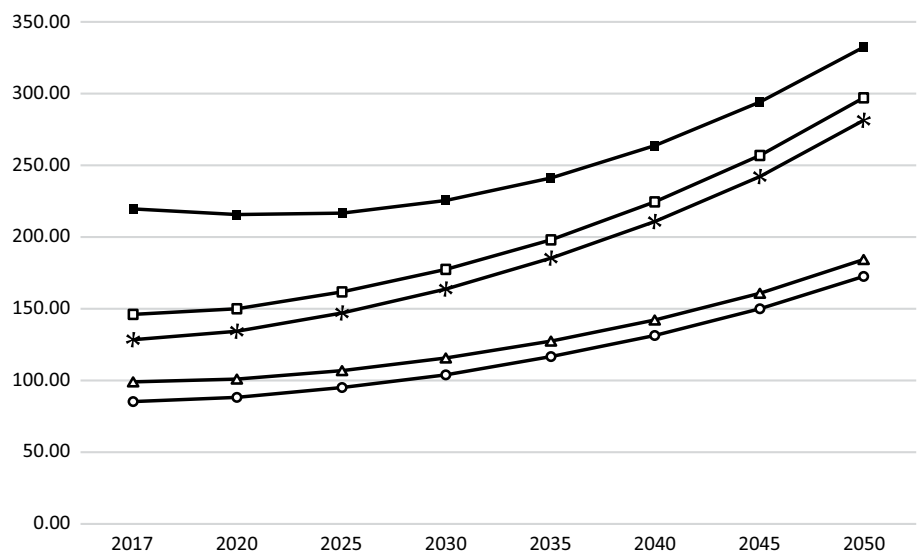

Figure 8.9 Simulation of trajectories of labor productivity in groups of oblasts in scenario I (thousand UAH, according to 2016 prices).

Source: Our own estimates.

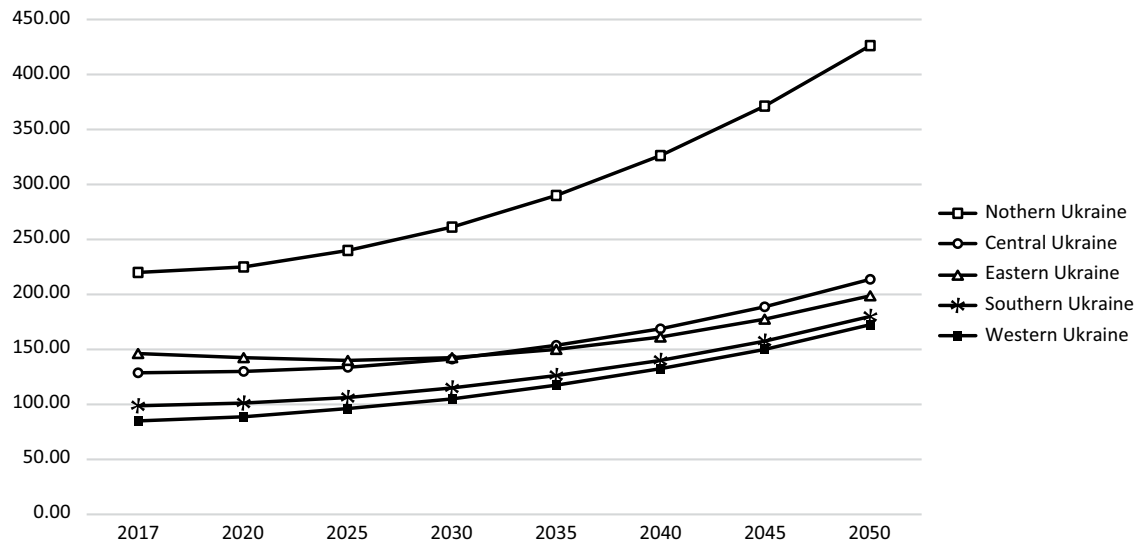

Figure 8.10 Simulation of trajectories of labor productivity in groups of oblasts in scenario II (thousand UAH, according to 2016 prices).

Source: Our own estimates. 

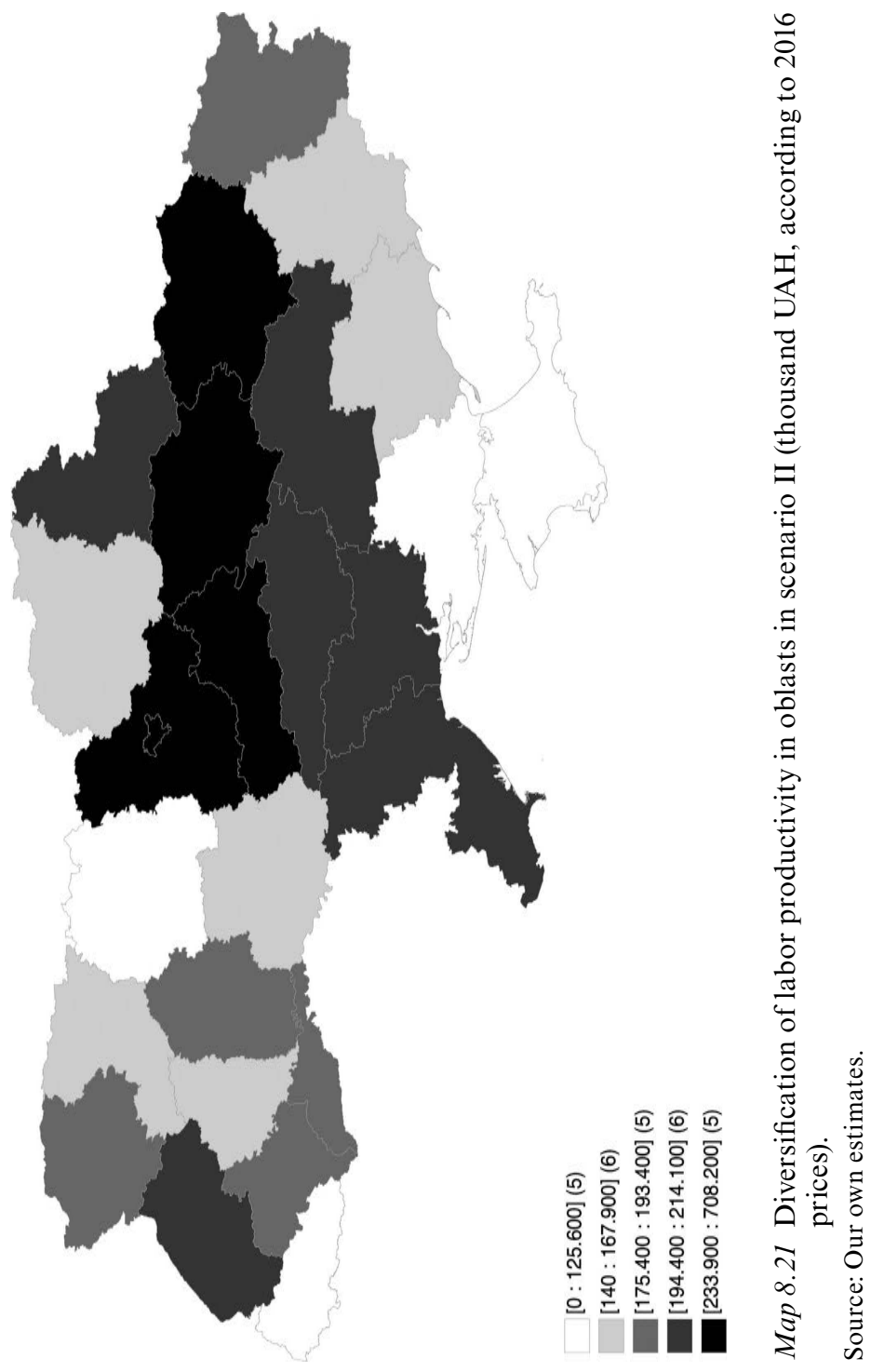


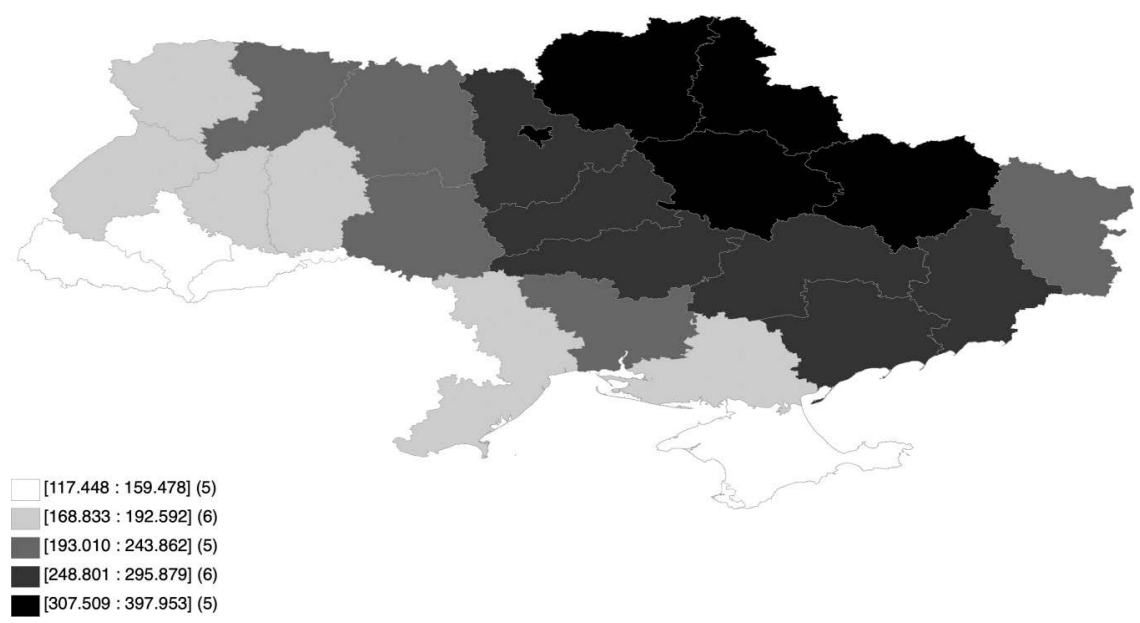

Map 8.22 Diversification of labor productivity in 2050 in oblasts in scenario III (thousand UAH, according to 2016 prices).

Source: Our own estimates.

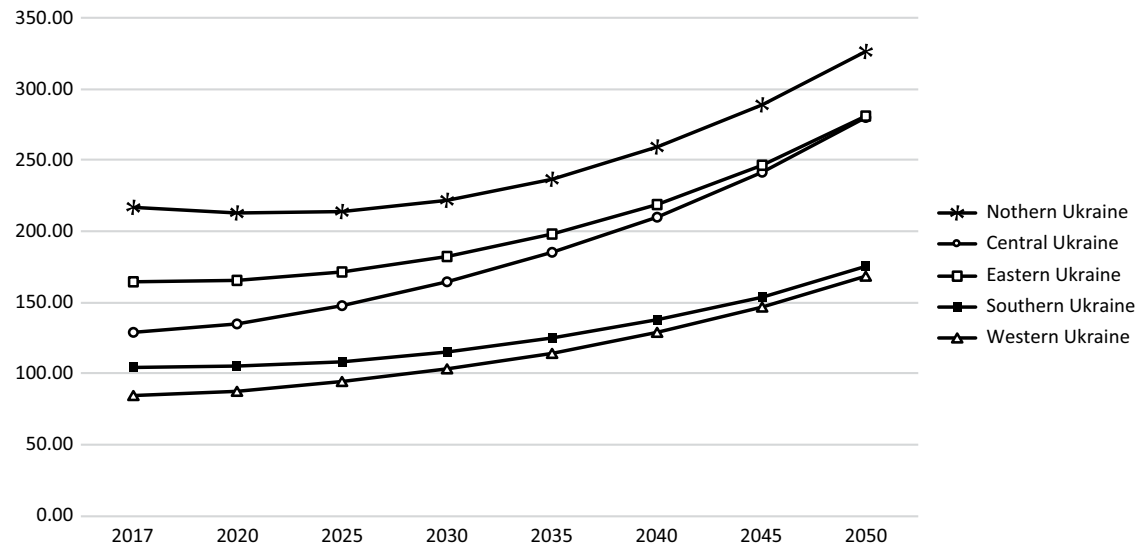

Figure 8.11 Simulation of trajectories of labor productivity in groups of oblasts in scenario III (thousand UAH, according to 2016 prices).

Source: Our own estimates. 


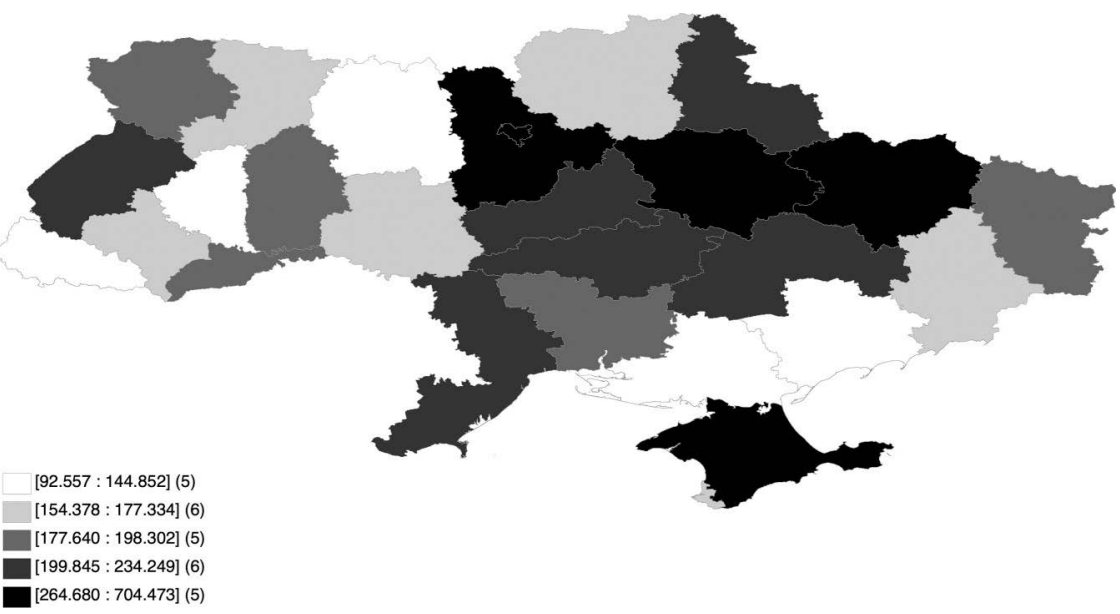

Map 8.23 Diversification of labor productivity in 2050 in oblasts in scenario IV (thousand UAH, according to 2016 prices).

Source: Our own estimates.

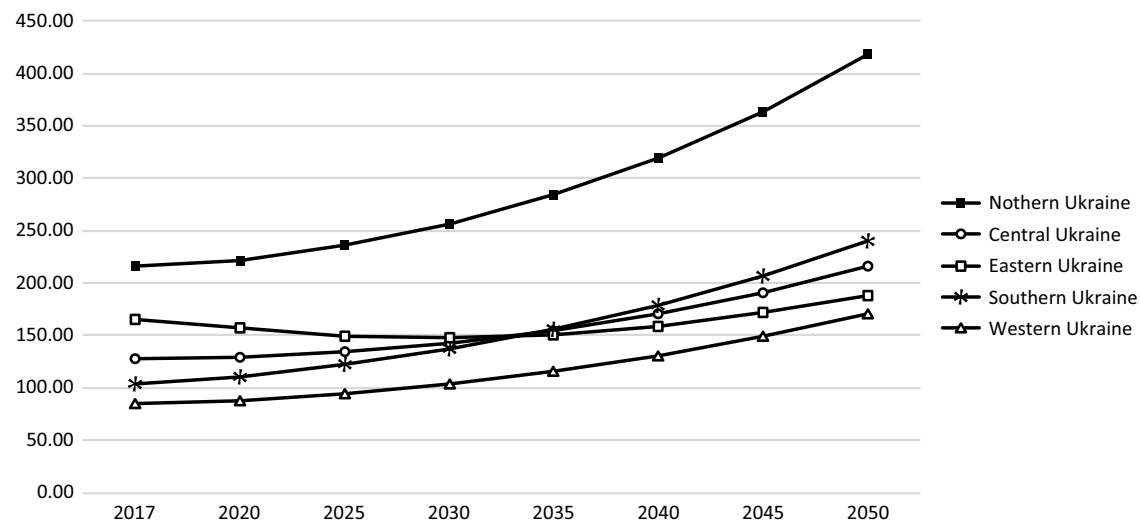

Figure 8.12 Simulation of trajectories of labor productivity in group of oblasts in scenario IV (thousand UAH, according to 2016 prices).

Source: Our own estimates. 


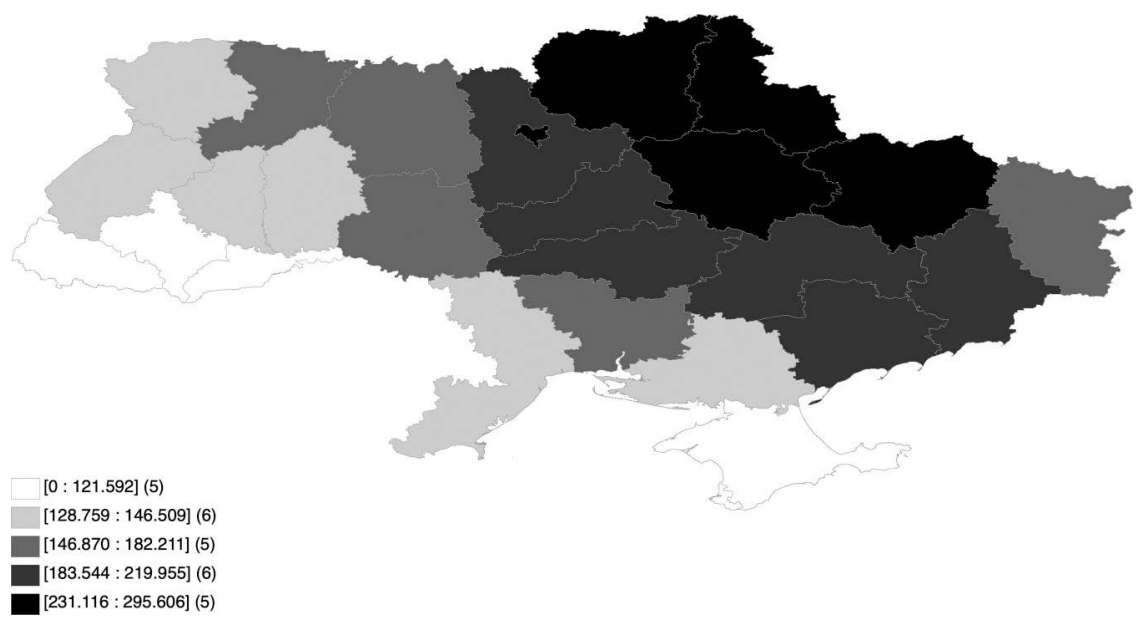

Map 8.24 Labor productivity in 2050 in voivodeships in scenario V (thousand PLN, according to 2016 prices).

Source: Our own estimates.

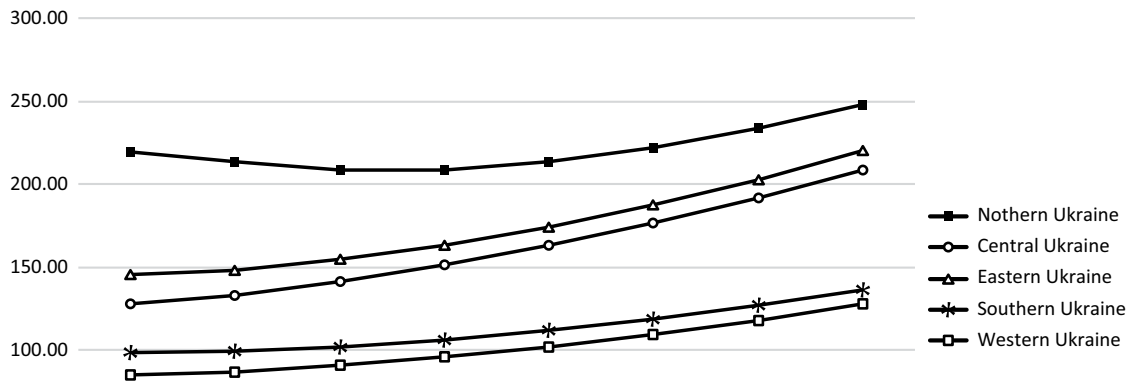

50.00

$\begin{array}{llllllll}0.00 & 2017 & 2020 & 2025 & 2030 & 2035 & 2040 & 2045\end{array}$

Figure 8.13 Simulation of trajectories of labor productivity in groups of oblasts in scenario V (thousand UAH, according to 2016 prices).

Source: Our own estimates. 


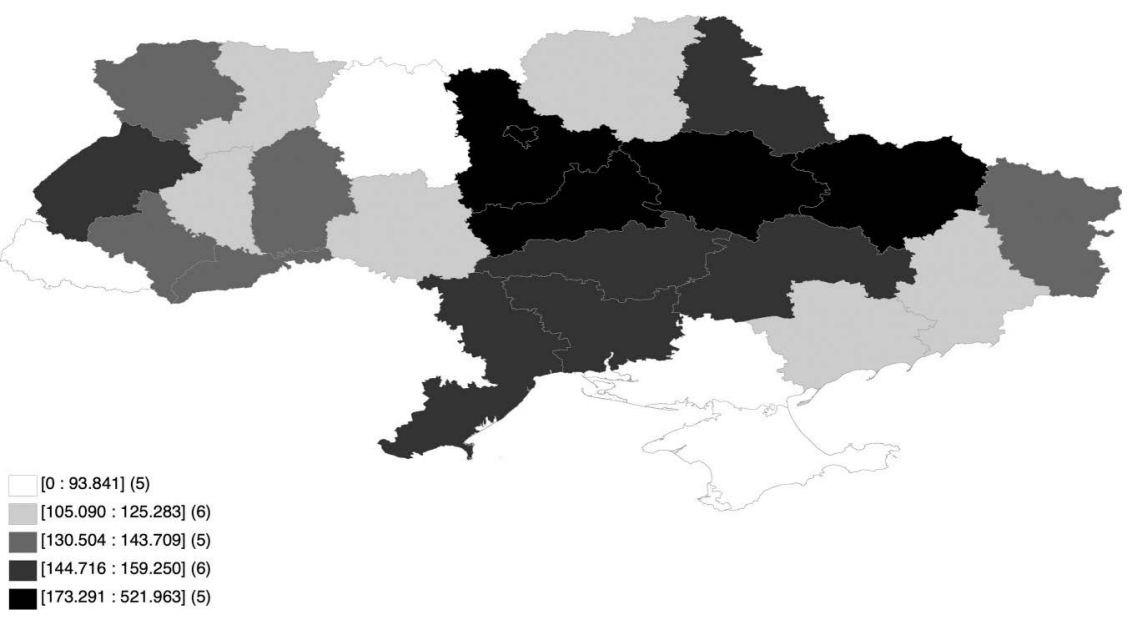

Map 8.25 Labor productivity in 2050 in oblasts in scenario VI (thousand UAH, according to 2016 prices).

Source: Our own estimates.

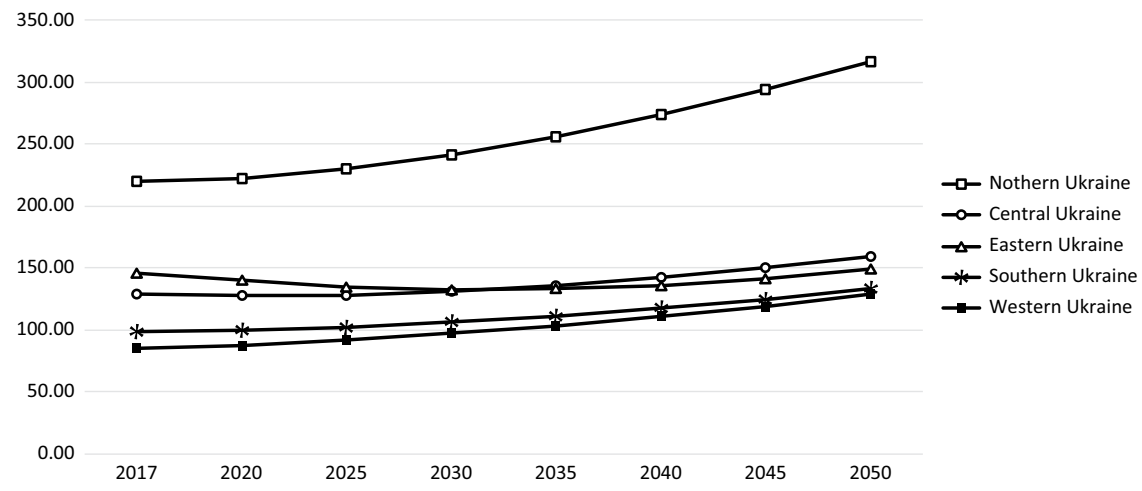

Figure 8.14 Simulation of trajectories of labor productivity in group of oblasts in scenario VI (thousand UAH, according to 2016 prices).

Source: Our own estimates. 


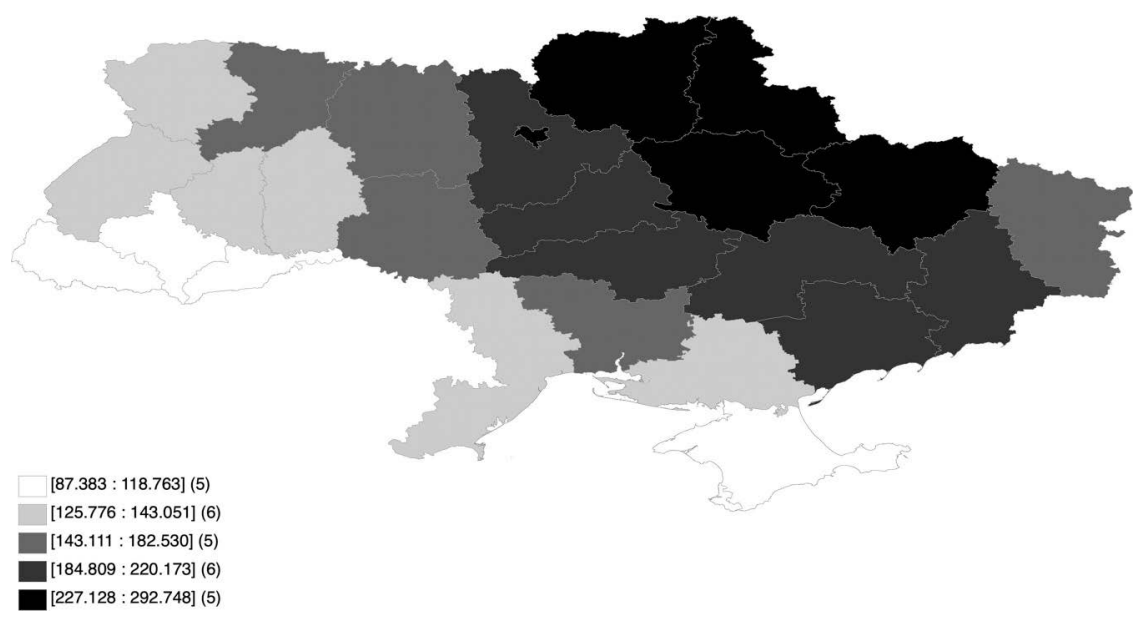

Map 8.26 Labor productivity in 2050 in oblasts in scenario VII (thousand UAH, according to 2016 prices).

Source: Our own estimates.

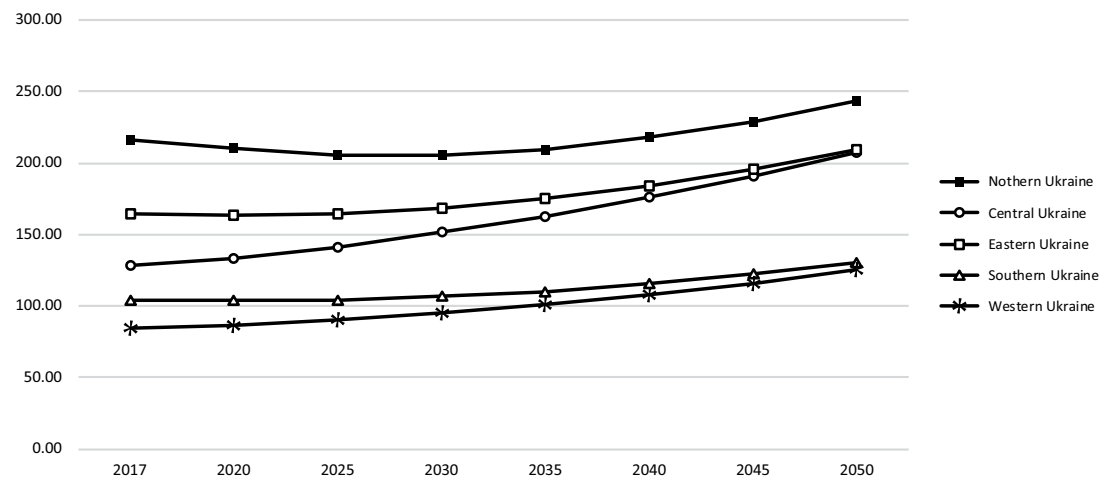

Figure 8.15 Simulation of trajectories of labor productivity in groups of oblasts in scenario VII (thousand PLN, according to 2016 prices).

Source: Our own estimates. 


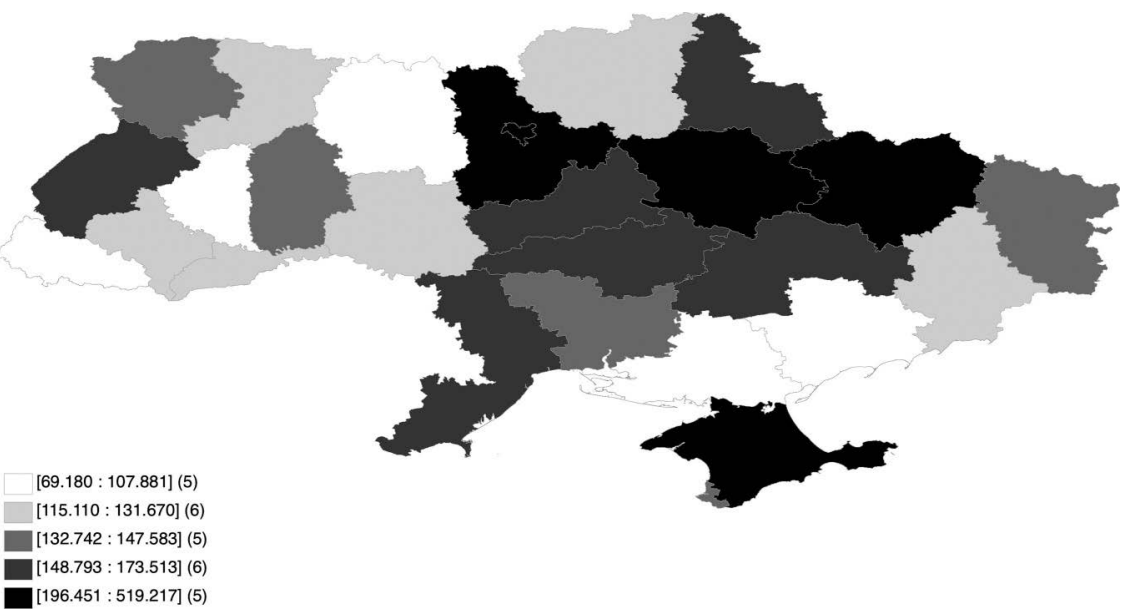

Map 8.27 Labor productivity in 2050 in oblasts in scenario VIII (thousand UAH, according to 2016 prices).

Source: Our own estimates.

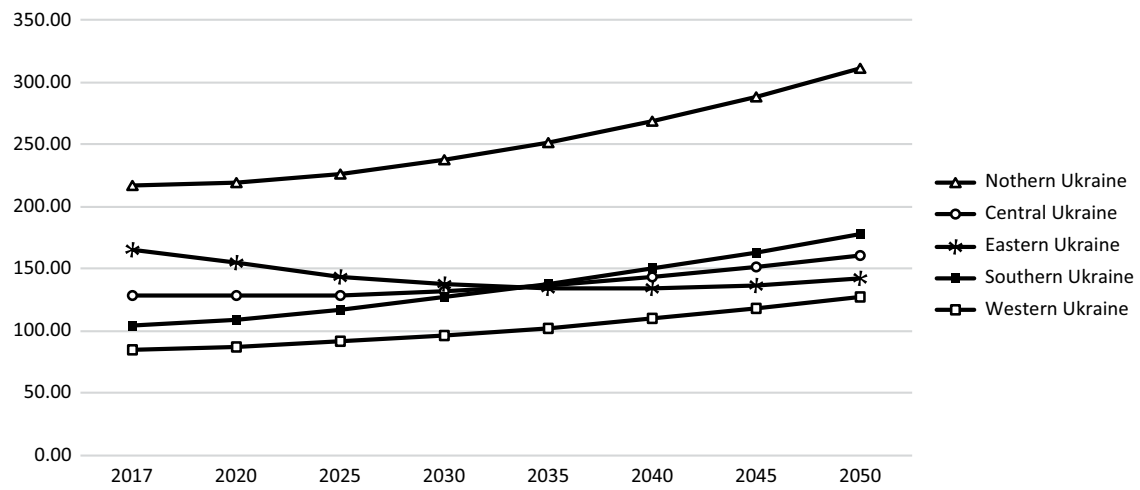

Figure 8.16 Simulation of trajectories of labor productivity in groups of oblasts in scenario VIII (thousand PLN, according to 2016 prices).

Source: Our own estimates. 


\section{Notes}

1 The notation $\forall i$ will mean $\forall i=1,2, \ldots, N$, where $N>2$ is the number of regions analyzed. The entries will be read in the same way in $\sum_{i}$ and $\prod_{i}$. In addition, about all macroeconomic variables analyzed at this point, we assume that they are functions differentiable with respect to time $t$, and the record $\dot{x}(t)=d x / d t$ will mean the derivative of the variable $x$ after time $t$ (i.e., economically speaking, the increase in the value of the variable $x$ at time $t$ ).

2 This is due to the fact that in the following considerations, labor productivity is expressed in thousand PLN, and the distance between provincial capitals in geographical minutes (mingeo), so the gravitational effects are expressed in million $\mathrm{PLN}^{2} /$ mingeo $^{2}$. The gravity effects in Ukraine are calculated similarly.

3 The external gravitational effects connecting voivodeships with other countries neighboring Poland were also counted. However, they turned out to be much weaker than those that connect these voivodeships with Germany. That is why they were omitted in the simulation analyzes.

4 When calculating the gravitational effects of the Kyiv oblast, the distance between the largest city of this oblast (Bila Tserkva) and the capitals of the other oblasts was taken into account.

5 Gravity effects from the other Ukrainian neighbors turned out to be much weaker than those from Poland or Russia. That is why they were omitted in simulation analyzes.

6 Simulations of labor productivity trajectories in groups of voivodeships or oblasts and their spatial diversity in 2050 in various scenarios are included in the annex.

7 In all scenarios, it was also assumed that the rate of depreciation of capital-labor ratio would be $14 \%$ (as it was historically). 